\title{
Imágenes, códigos y comunicación: un análisis del arte rupestre en el Extremo Sur del Macizo del Deseado (Patagonia, Argentina)
}

Agustín Acevedo* y Danae Fiore*
Recibido:

14 de marzo de 2019

Aceptado:

25 de septiembre de 2019

\section{Resumen}

En este trabajo se evalúan las reglas de composición que vinculan motivos rupestres y soportes rocosos, comparando para ello un total de 1.273 motivos y 76 tipos de motivos (TM) registrados en 33 sitios de dos localidades arqueológicas de la región centro-sur de Patagonia (Argentina). Los análisis demuestran que: a) los emplazamientos de los motivos en los soportes rocosos no siguen reglas claras de composición visual y b) del total de TM, las dos localidades comparten solo 14, lo cual indicaría la existencia de bajos niveles de comunicación visual entre ambas. Esto es discutido en función de diferentes formas de integración de cada localidad dentro de circuitos mayores de movilidad e intercambio de información a escala regional. A su vez, los 14 TM compartidos representan más del $60 \%$ de la producción rupestre de cada una, lo cual implica un claro énfasis de selección de determinadas porciones del repertorio para la producción artística de cada localidad. Se argumenta entonces que la comunicación visual generada por cazadores-recolectores en ambas localidades habría sido más fluida y menos reglada que lo esperado en términos generales de las teorías de comunicación, más acorde con un bajo grado de control social característico de estas sociedades.

\section{Images, codes and communication: an analysis of rock art in the} Southern Deseado Massif (Patagonia, Argentina)

\begin{abstract}
In this paper, we assess the composition rules underlying the relationships between rock art motifs and bedrocks, by comparing a total of 1.273 motifs and 76 motif types (MT) recorded at 33 sites in two archaeological localities of south-central Patagonia (Argentina). Our analyses show that: a) the display of rock art motifs on the bedrocks do not follow clear visual composition rules; b) out of the total number of MT, both localities only share 14, which would entail the existence of low levels of communication between them. We discuss this regarding the different potential relations that each locality may have had within wider mobility and information exchange circuits at
\end{abstract}

Palabras clave

Cazadores-recolectores Comunicación visual Reglas de composición Patagonia

\section{Keywords}

Hunter-gatherers Visual communication Composition rules Patagonia 
a regional scale. In turn, the 14 shared MT represent more than $60 \%$ of the rock art production of each locality, which implies a clear emphasis on the selection of specific portions of the repertoires for the artistic production in each locality. It is argued that visual communication generated by hunter-gatherers in both localities would have been more fluid and less regulated than expected according to the general terms of communication theories, in accordance with a low degree of social control, characteristic of this type of societies.

\section{Introducción}

Este trabajo analiza aspectos de la comunicación visual de información entre grupos cazadores-recolectores, a través del estudio de recurrencias y discontinuidades en la creación de tipos de motivos rupestres en dos localidades arqueológicas de Patagonia centro-meridional (región Extremos Sur del Macizo del Deseado, Patagonia, Argentina), evaluando el grado de vinculación existente entre ellas. La región bajo estudio (en adelante ESMD), se encuentra ubicada en el centro de la provincia de Santa Cruz, al norte del río Chico y al este del municipio Gobernador Gregores. La misma está compuesta por dos localidades arqueológicas, distantes unos $c a .30 \mathrm{~km}$ entre sí, con características geológicas y topográficas diferentes (Figura 1):

a) La Gruta, caracterizada por un relieve irregular (situado entre cotas de $300 \mathrm{y}$ $350 \mathrm{~m}$ s.n.m.) que alterna lomadas redondeadas y cerritos aislados con lagunas temporarias rodeadas por afloramientos rocosos de ignimbritas y areniscas coquinoideas (Panza y Marín, 1998);

b) Viuda Quenzana, caracterizada por un relieve cortado e irregular (situado entre cotas de 300 y 400 m s.n.m.) compuesto por lomadas suaves - con afloramientos rocosos de ignimbritas- interrumpidas por cañadones y zanjones de reducidas dimensiones que vierten sus aguas estacionales en depresiones sin desagüe (Panza y Marín, 1998).

Ambas localidades se encuentran en cercanía de otras localidades arqueológicas (e.g. La Martita, La María, El Verano, El Ceibo; Figura 1), caracterizadas tanto por sus producciones rupestres, como por sus largas secuencias de ocupación que van desde el Pleistoceno-Holoceno hasta el Holoceno tardío (c.f. Aguerre, 1987, 2003; Cardich, 1979, 1987; Durán, Gil, Neme y Gasco, 2003; Paunero et al., 2005; entre otros). En este contexto, excavaciones realizadas en La Gruta (sitios LG1, LG2 y LG3) y Viuda Quenzana (sitios VQ7 y VQ8), han proporcionado evidencias de ocupaciones discontinuas en la región desde la transición Pleistoceno-Holoceno hasta el Holoceno tardío ( $c a .10 .800$ a 300 años AP), que son consistentes con el cuadro temporal de ocupaciones humanas exhibido por los sitios y localidades cercanas previamente mencionadas (Brook, Franco, Ambrústolo, Mancini, Wang y Fernandez, 2015; Franco, Ambrústolo, Acevedo, Cirigliano y Vommaro, 2013; Franco, Martucci, Ambrústolo, Brook, Mancini y Cirigliano, 2010).

En trabajos recientes hemos planteado la existencia de diferencias entre los patrones de marcación visual del espacio en La Gruta y Viuda Quenzana, relacionadas con una posible complementariedad funcional entre localidades, a partir de: a) la asociación de las características del arte de La Gruta con un patrón de ocupaciones predominantemente logístico; y b) la asociación de las características del arte de Viuda Quenzana con un patrón de ocupaciones predominantemente residenciales ( $c f$. Acevedo, 2017; Acevedo y Fiore, 2019). Sobre esta base, el presente trabajo se propone 

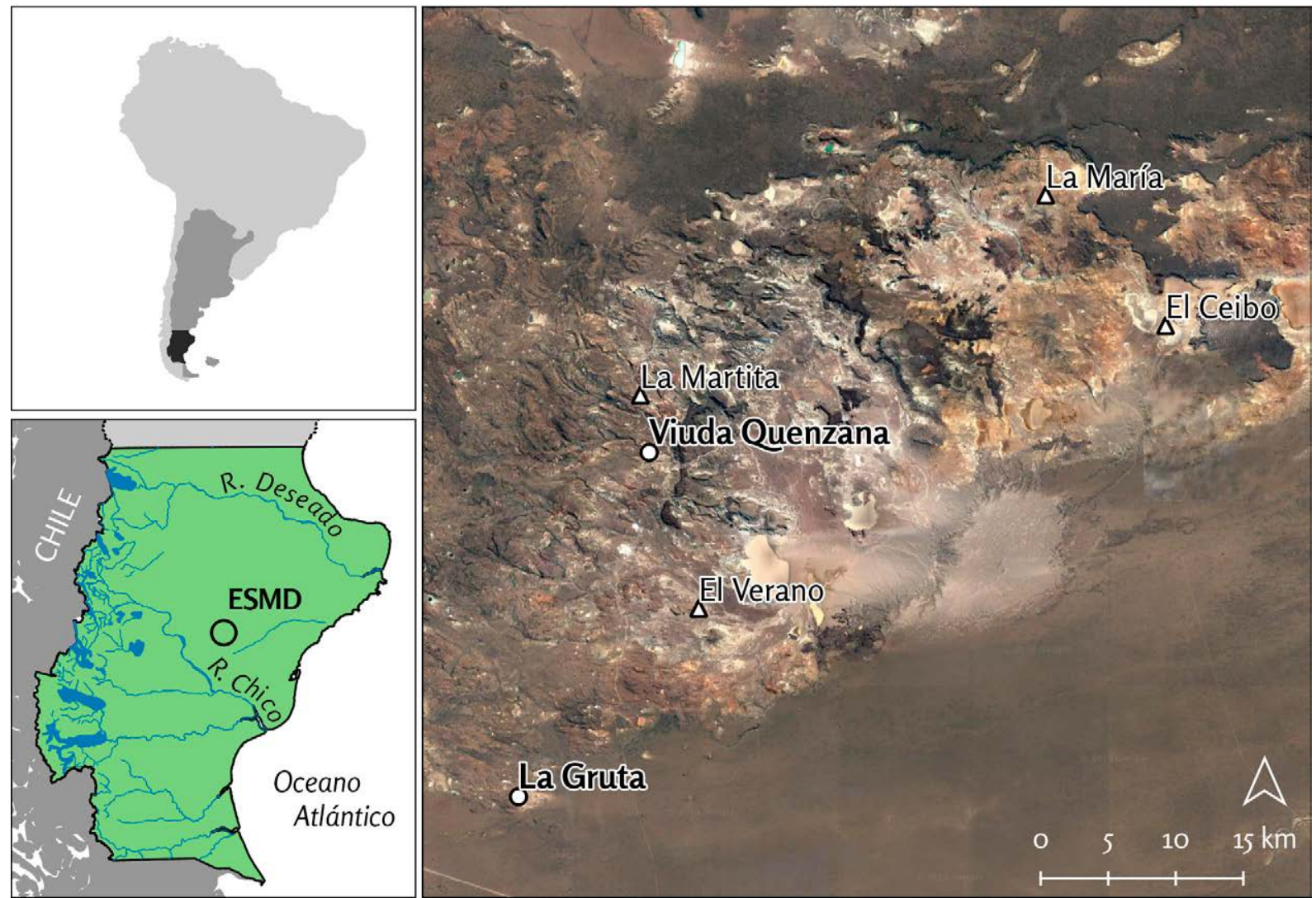

Figura 1. Localidades arqueológicas de la región Extremo Sur del Macizo de Deseado analizadas en este trabajo (círculos) y localidades vecinas (triángulos) (Google Earth).

evaluar el grado de comunicación visual existente entre ambas localidades mediante un análisis composicional de sus motivos rupestres.

\section{Antecedentes}

Las publicaciones antecedentes sobre el arte rupestre de La Gruta y Viuda Quenzana son pocas y se estructuran en torno a dos tipos objetivos: 1) descriptivos-empíricos; y 2) cronológicos-estilísticos. En el primer conjunto de publicaciones se enmarcan los trabajos arqueológicos iniciales en la región consistentes en descripciones detalladas de los primeros sitios rupestres identificados en cada localidad, acompañadas por inferencias difíciles de corroborar sobre los referentes representados en algunos motivos (e.g. Menghin, 1952; Molina, 1972). El segundo conjunto de publicaciones consiste de trabajos orientados hacia la clasificación morfológica de los motivos de cada localidad y su ordenamiento temporal utilizando indicadores provenientes de secuencias macro-regionales de producción rupestre y de excavaciones en localidades vecinas (e.g. Gradin y Aguerre, 1983; Menghin, 1957). Siguiendo este procedimiento Menghin (1957) atribuyó el arte rupestre de La Gruta al Estilo de Pisadas, que ubicó temporalmente entre ca. 6000 y 4000 años AP. Por su parte, Gradin y Aguerre (1983) y Gradin (2001), asignaron la producción rupestre de La Gruta al Grupo estilístico E (que ubicaron en ca. 1700 años AP) y la de Viuda Quenzana a los Grupos estilísticos B, B.1 y D (que ubicaron temporalmente en $c a$. 7000, 4500 y 1700 años AP, respectivamente). Es necesario destacar que, ambos conjuntos de publicaciones tienen en común el no haber trabajado sobre todos los sitios con arte de cada localidad, sino solamente sobre una parte del total. 
Las inferencias sobre las posibles formas de ocupación de una y otra localidad, en base a sus producciones rupestres, no se plantean aquí en términos absolutos. Es factible que, a través del tiempo, ambos espacios hayan soportado distintas estrategias de ocupación. Esto ha sido ya señalado para el caso de La Gruta en trabajos anteriores (cf. Cirigliano, 2016; Acevedo, 2018). En este sentido, los planteos aquí realizados son esquemas generales que necesitan ser contrastados estratigráficamente.

2. Dicha práctica de producción puede ser, en sí misma, significativa para los creadores del arte (Fiore y Podestá, 2006).
En este contexto, las sucesivas publicaciones generadas por nuestro equipo sobre el arte rupestre de La Gruta y Viuda Quenzana han buscado incrementar progresivamente tanto el caudal de información sistemáticamente producida, como los niveles de complejidad analítica. Así, se comenzó con la presentación de la totalidad de los sitios registrados en ambos espacios y la caracterización morfológica y técnica de sus repertorios rupestres (Acevedo, 2018; Acevedo, Fiore y Franco, 2013; Fiore y Acevedo, 2018; Franco et al., 2013). Se continuó con la inserción de estas producciones dentro del contexto macro-regional patagónico, señalando sus similitudes y diferencias técnicas y morfológicas con otras regiones de Patagonia (e.g. sur del Macizo del Deseado, meseta del Lago Strobel, margen norte del río Santa Cruz; cf. Acevedo et al., 2013; Fiore y Acevedo, 2015). Y, en forma más reciente, se ha comenzado a analizar el arte de cada localidad —individualmente - en función de sus propias dinámicas internas de ocupación humana y —conjuntamente- en función de las dinámicas de ocupación humana de la región en general (Acevedo, 2018; Fiore y Acevedo, 2018; Fiore, Acevedo y Franco, 2017).

En el marco de estos trabajos se propuso que las diferencias observadas entre el arte rupestre de La Gruta y Viuda Quenzana (en términos de cantidad de sitios, motivos, tipos de motivos, colores, superposiciones, sus distribuciones espaciales intralocalidad y las características de los sitios utilizados), responderían a distintas formas de marcación visual del terreno, relacionadas con diferentes estrategias cazadorasrecolectoras en el uso de los espacios, adoptadas en función de la oferta diferencial de recursos existente entre una y otra localidad ( $c f$. Acevedo 2017; Acevedo y Fiore, 2019). Así, en el caso de Viuda Quenzana, que presenta una mayor oferta de recursos (reparos rocosos, materias primas líticas, enclaves potencialmente utilizables para el aprovisionamiento de pigmentos naturales y fuentes de agua superficial), se observó un patrón de marcación visual del espacio altamente visible, consistente con una estrategia de ocupación principalmente residencial. En cambio, en el caso de La Gruta, que ofrece una menor oferta de recursos, se observó un patrón de marcación visual del espacio poco visible, consistente con el tipo de producción rupestre que sería esperable encontrar en espacios de ocupaciones principalmente logísticas ${ }^{1}$. Dichos planteos son acordes con proposiciones previas realizadas por Franco y equipo desde de otras líneas de evidencias (Franco, Ambrústolo y Cirigliano, 2012; Franco, Ambrústolo y Vetrisano, 2015a; Franco, Brook, Mancini y Vetrisano, 2015b; Franco, Castro, Cirigliano, Martucci y Acevedo, 2011; Franco et al., 2010; entre otros). Desde este escenario de potencial complementariedad funcional entre localidades se propone analizar el grado de vinculación existente entre sus producciones rupestres.

\section{Marco teórico: de composición de imágenes y comunicación visual en sociedades cazadoras-recolectoras}

La producción de arte rupestre implica un amplio conjunto de factores - económicos, políticos, ideológicos, tecnológicos, cognitivos, etc.- que operan de manera simultánea en la práctica ${ }^{2}$ y son distinguibles analíticamente para su estudio (Aschero, 1988; Conkey, 1984; Fiore, 1996, 2009; Morphy, 1994). A su vez, su creación puede responder a diversas finalidades (religiosas, simbólicas, decorativas, indentitarias, expresivas, etc.), dependiendo de su contexto de uso (Aschero, 1988; Carden, 2009; Conkey, 1984; Domingo Sanz, Fiore y May, 2008; Fiore, 2014; Ucko y Rosenfeld, 1967; Whitley, 1994; entre otros). En términos analíticos, estos diferentes usos de las imágenes rupestres han sido agrupados por distintos autores en dos grandes unidades de motivación que no son mutuamente excluyentes: estética y comunicativa (Layton, 1991; Morphy, 1994). La motivación estética del arte remite a la intención de generar un efecto sensorial mediante su percepción visual, a partir de la estructuración formal de las cualidades plásticas de las imágenes (Gell, 1998; Heyd y Clegg, 2005; Layton, 1991). La motivación comunicacional del arte es entendida como una forma de expresión de contenidos 
(religiosos, identitarios, políticos, etc.) mediante imágenes ordenadas en función de una serie de reglas que generan el proceso comunicativo entre emisor/es y receptor/es al permitirles codificar y de-codificar información (Layton, 1991; Llamazares, 1992). Ambos tipos de motivación (así como las diversas finalidades que se desprenden de ellas) pueden operar de forma complementaria, aunque en ocasiones alguna pueda imponerse más sobre la otra (Aschero, 1988; Conkey, 1984; Gell, 1998; Hernández Llosas, 1985; Layton, 1991; Morphy, 1994; entre otros).

De acuerdo con la semiótica, el concepto de comunicación refiere a todos aquellos procesos en los que se emiten y reciben mensajes basados en códigos (Eco, 2013; Morris, 1985; Peirce, 1974). En el caso específico de la comunicación visual, estos mensajes están construidos en imágenes. De este modo, sostener que el arte rupestre puede desempeñar funciones como vehículo para la transmisión de información entre individuos implica - ineludiblemente - considerar la existencia de un código subyacente que posibilite la emisión (codificación) y recepción (decodificación) de mensajes visuales, es decir: la comunicación (Giraudo y Martel, 2015; Llamazares, 1986, 1992; entre otros). Los códigos visuales cumplen las funciones esenciales de todo código en un proceso de comunicación: codificar la información proveniente de una fuente (e.g. del mundo físico, el mundo simbólico), reduciendo y ordenando sus unidades pertinentes, para hacerla comunicable y comprensible (Eco, 2013). El rasgo que distingue a la comunicación visual de otras formas de comunicación es que el accionar del código está mediado por la percepción visual, que filtra (selecciona), crea y categoriza estímulos visuales, organizándolos en imágenes reconocibles (culturalmente significativas) a partir de experiencias culturales previas (Anzorena, 1998; Arnheim, 1972, 1985; Eco, 2013; Gombrich, 1984; Villafañe, 2006; Washburn, 1983).

Acorde con esta perspectiva, la definición de imagen rupestre utilizada en este trabajo remite a toda composición gráfica resultante del emplazamiento de uno o varios motivos sobre un soporte rocoso no transportable. Los motivos, por su parte, son entendidos como entidades visuales de menor escala producto de la articulación de elementos decorativos básicos (e.g. líneas, puntos, figuras) en forma individual, reiterada y/o combinada (Aschero, 1988; Aschero y Martel, 2003-2005; Basile y Ratto, 2011; Gradin, 1978; Hernández Llosas, 1985). Estas definiciones destacan el carácter estructural de las imágenes y los motivos como composiciones organizadas sobre la base de un código que selecciona, incluye/excluye y dispone espacialmente en el soporte los elementos pertinentes para la construcción de expresiones gráficas culturalmente significativas (Dondis, 2015; Eco, 2013; Juanola Terradellas, Sala Plana, Vallés Villanueva y De Arroyo 2001; Villafañe, 2006).

De esta manera, la apariencia final de los motivos y conjuntos de motivos participantes de un sistema de comunicación está determinada por su composición visual, es decir, la forma en que las unidades visuales (elementos que forman motivos y motivos que forman conjuntos) son articuladas por el código a través de un conjunto de reglas de composición que actúan sobre:

a) las características visuales básicas de los motivos: su forma, color, técnica, posición, orientación y vínculo con el soporte (Acevedo, Fiore, Franco y Ocampo, 20122014; Leroi-Gourhan, 1967; Llamazares, 1992); denominadas como reglas norelacionales de composición visual (sensu Fiore, 2016), ya que éstas no dependen de la relación entre dos o más motivos en el espacio plástico;

b) sus vínculos relacionales con otros motivos: sus combinaciones, posiciones relativas y superposiciones sobre o debajo (Acevedo et al., 2012-2014; Leroi-Gourhan, 1967; Llamazares, 1992); denominadas como reglas relacionales de composición visual (sensu Fiore, 2016), ya que éstas dependen directamente de la relación entre los motivos en el espacio plástico. 
La identificación de reglas relacionales de composición visual requiere primeramente conocer: a) el repertorio de tipos de motivos utilizados en las composiciones de las imágenes; y b) las reglas no-relacionales, en tanto que éstas permiten identificar las elecciones y prácticas más básicas de composición y emplazamiento de cada tipo en el espacio plástico del soporte rocoso. Dado que el propósito de este trabajo consiste en generar un primer acercamiento sistemático al estudio de la comunicación visual existente entre las producciones rupestres de La Gruta y Viuda Quenzana, se abocará al cumplimiento de ambos objetivos dejando la identificación de las reglas relacionales para un futuro trabajo.

Para finalizar, cabe destacar que la búsqueda de reglas de composición visual compartidas entre diferentes localidades puede arrojar luz sobre la relación temporal existente entre sus producciones rupestres, tarea que - más allá del solapamiento temporal señalado por investigadores antecedentes (ver arriba) - siempre reviste dificultades ante la ausencia de información cronológica absoluta. Esto es posible porque, en términos de reglas, las expectativas para procesos de comunicación visual sincrónicos y diacrónicos son diferentes (Davidson, en prensa; Fiore y Acevedo, 2015). En el caso de la comunicación visual sincrónica o cuasi-sincrónica (donde hay penecontemporaneidad entre la producción y la visualización e interpretación de los motivos), estarían dadas las condiciones propicias para una transmisión efectiva de información entre observadores y productores y, por lo tanto, sería esperable la manifestación de un código visual plenamente compartido entre localidades (es decir, reglas relacionales y no-relacionales de composición). En cambio, en el caso de la comunicación visual diacrónica (donde hay distancia temporal entre la producción y la visualización de los motivos), no estarían dadas las condiciones propicias para la transmisión efectiva de información, ya que el código visual de los productores no habría sido necesariamente compartido de manera completa por los observadores. Por lo tanto, en este escenario sería esperable que ambas localidades compartieran una parte del código visual, centrada en los elementos básicos de composición visual de las imágenes rupestres: el repertorio de tipos de motivos y las reglas no-relacionales.

\section{Metodología: la búsqueda de reglas de composición a distintas escalas}

En función del objetivo planteado y los conceptos teóricos desarrollados, se diseñó una metodología de registro y análisis de datos a escala de sitio, panel y motivo, orientada hacia la búsqueda de patrones que den cuenta de la existencia de reglas no-relacionales de composición visual compartidas entre localidades (Fiore, 2016).

El registro de información en el campo se realizó mediante fotografías y planillas de relevamiento diseñadas para recoger datos sobre el arte de cada localidad a escala de sitio, panel y motivo (Fiore, 2009, 2016; Hernández Llosas, 1985). El llenado de planillas se llevó adelante siguiendo un protocolo específico, que define las variables a relevar y sus estados posibles para alcanzar mayores niveles de consistencia y rigurosidad en el ingreso de datos, reduciendo el margen de error inter-observador. El registro sistemático del arte se desarrolló con la ayuda de fotografías etiquetadas digitalmente para dar cuenta del número de panel dentro de cada sitio y el número de motivo dentro de cada panel.

Durante la etapa de análisis, se complementó el registro fotográfico de campo con la aplicación del software DStretch-ImageJ que permite aumentar digitalmente la visibilidad de motivos obliterados (Harman, 2008). La información relevada se volcó en una base de datos de múltiples escalas (sitio, panel y motivo) vinculadas entre sí por la asociación del número de sitio y número de panel a cada motivo registrado (Fiore, 2009). Sobre la información recolectada se realizaron análisis estadísticos univariados y bivariados, a diferentes escalas y entre escalas, que permitieron describir los datos y 
explorar tendencias significativas para la búsqueda de patrones sobre los cuales inferir la presencia de reglas en la composición plástica de los motivos y sus relaciones con el soporte que los contiene (Fiore, 2009, 2016). La definición de regla adoptada en este trabajo remite a un comportamiento recurrente que se expresa en una alta frecuencia de asociación entre dos estados de dos variables (un tipo de motivo y un color, un tipo de motivo y una superficie general del soporte, etc.). Para identificar operativamente la presencia comportamientos reglados se considera como umbral mínimo aquellos casos de proporciones iguales o superiores al 50\%, sobre frecuencias mayores o iguales a cinco.

Este trabajo se organiza en torno a tres escalas: sitio, panel y motivo. La escala de sitio es la máxima unidad de registro y análisis utilizada. Por sitio (rupestre) se entiende a toda concentración discreta de motivos en el interior de soportes rocosos con límites precisables a partir de su morfología (e.g. alero, cueva, paredón) (Hernández Llosas, 1985; Re, 2010). A esta escala se registró información sobre un total de 25 variables ${ }^{3}$; de las cuales, en función de los objetivos planteados, sólo se retomará la variable tipos de $\operatorname{motivos}^{4}$ (por sitio).

La segunda escala de registro y análisis es el panel, entendido como una unidad y/o porción discreta de soporte rocoso que contiene uno o varios motivos rupestres (relacionados visualmente entre sí por proximidad espacial), cuyos límites se establecen siguiendo criterios convencionales (e.g. circunscripción por accidentes microtopográficos en torno al panel, cambios significativos en la orientación del soporte y/o espacios circundantes vacíos de imágenes) (Fiore y Acevedo, 2018; Loendorf, 2001). A esta escala se registró información sobre 10 variables, de las cuales serán retomadas cuatro relativas a los atributos de los soportes rocosos, a saber: orientación cardinal del panel (norte, sur, este, oeste, etc.), superficie general del panel (cóncavo, convexo y/o plano), ángulo respecto del suelo (horizontal, vertical, agudo y obtuso) y microtopografía del panel (reparo, grietas, nichos, salientes, etc.).

Por último, la escala mínima de registro y análisis de este trabajo es el motivo, que se define como: la expresión gráfica resultante de la utilización de uno o varios elementos decorativos básicos (empleados de manera única, reiterada y/o combinada), ejecutada mediante un elemento único de trazo unitario y/o mediante elementos discretos con una proximidad espacial notoria entre sí que se unen para formar una sola entidad visual mayor (Aschero, 1988; Aschero y Martel, 2003-2005; Fiore y Acevedo, 2018; Gradin, 1978; Hernández Llosas, 1985). A esta escala se registró información sobre 26 variables, de las cuales sólo serán retomadas siete vinculadas a los aspectos técnicos y formales de los motivos: número de panel al que pertenece, tipo de motivo, técnica de ejecución, color Munsell (1994), dirección (vertical, horizontal, diagonal, etc.), tratamiento gráfico de la forma (lineal, areal, perimetral, etc.) y modo de aplicación del trazo (continuo y/o discontinuo).

\section{Resultados}

\section{Caracterización de las producciones rupestres de La Gruta y Viuda Quenzana}

La Gruta (en adelante LG) comprende una superficie aproximada de $6 \mathrm{~km}^{2}$ y se divide en dos sectores conformados por dos lagunas temporales distantes ca. 1,2 km entre sí: Laguna 1 (con cinco sitios: LG2, 3, 5, 6 y 7) y Laguna 2 (con dos sitios: LG1 y 4) (Figura 2A). La producción rupestre de la localidad registra un total de 168 motivos distribuidos entre 52 paneles. Estos 168 motivos se agruparon en un repertorio de 20 tipos de motivos (en adelante TM), siendo los más frecuentes negativos de manos (N
3. Para más detalles sobre las variables registradas a cada escala cf. Acevedo (2017).

4. Por tipo de motivo se entiende a un conjunto recurrente de atributos morfológicos que permiten la clasificación de varios casos de motivos en una misma categoría de diseño, la cual es morfológicamente distinta a otras categorías (Aschero, 1988; Fiore, 2011; Hernández Llosas, 1985). 
Arqueología 26(2) mayo-agosto: 127-155 (2020)— A. Acevedo y D. Fiore
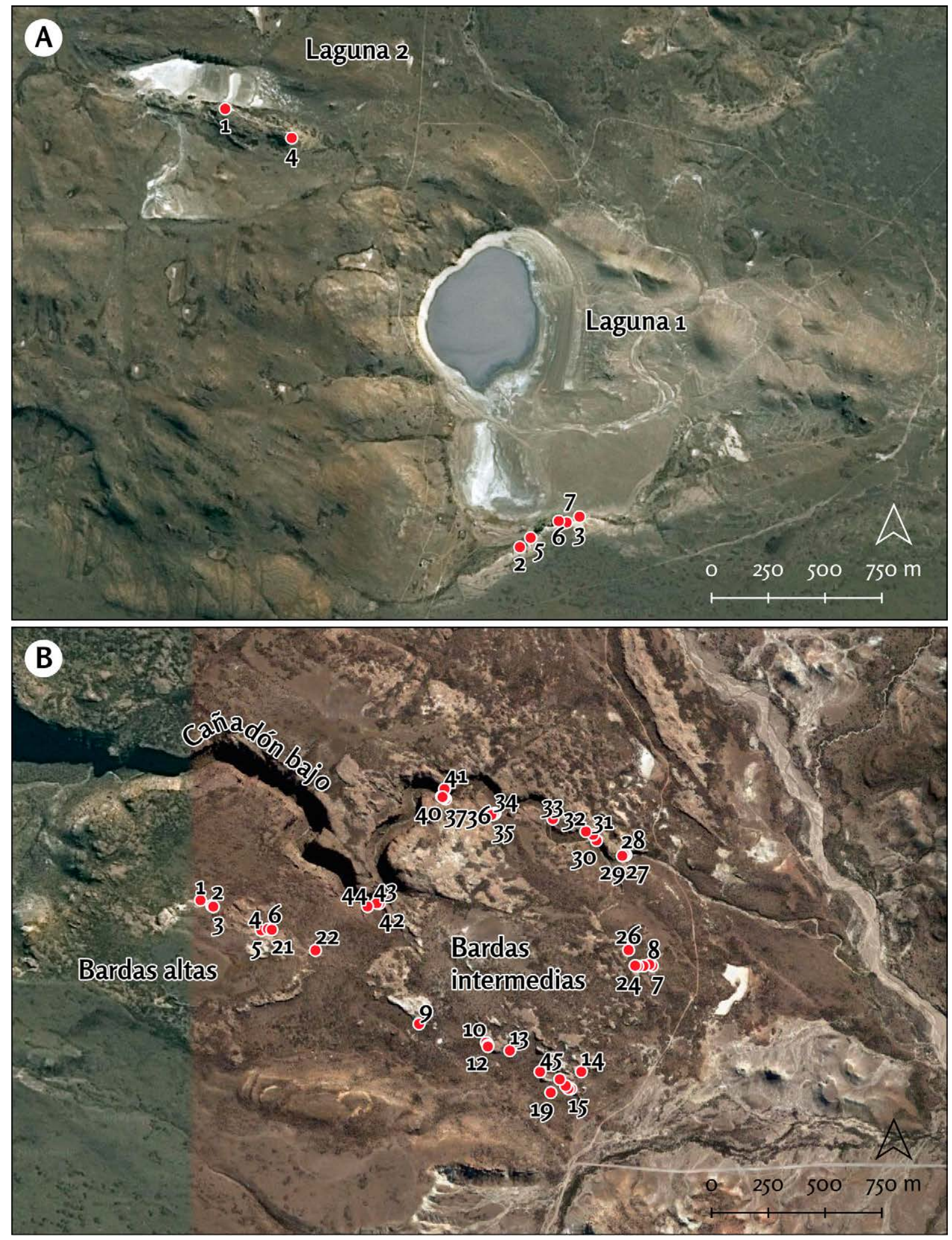

Figura 2. A) Sitios con arte rupestre de LG;B) sitios con arte rupestre de VQ (Google Earth). 


\begin{tabular}{|c|c|c|c|c|c|c|c|}
\hline \multirow[b]{2}{*}{ CM } & \multirow[b]{2}{*}{ TM } & \multicolumn{2}{|c|}{ LG } & \multicolumn{2}{|c|}{ VQ } & \multicolumn{2}{|c|}{ Total } \\
\hline & & $f$ & $\begin{array}{c}\mathrm{n} \\
\text { sitios }\end{array}$ & $f$ & $\begin{array}{c}\mathrm{n} \\
\text { sitios }\end{array}$ & $f$ & $\begin{array}{c}\mathrm{n} \\
\text { sitios }\end{array}$ \\
\hline \multirow{8}{*}{$\begin{array}{l}\text { Geométricos } \\
\text { simples }\end{array}$} & Almenados & 2 & 1 & 1 & 1 & 3 & 2 \\
\hline & Líneas curvas & 2 & 2 & 24 & 10 & 26 & 12 \\
\hline & Líneas sinuosas & 1 & 1 & 30 & 11 & 30 & 12 \\
\hline & Meandros & 2 & 1 & 3 & 4 & 5 & 5 \\
\hline & Óvalos & 2 & 1 & 3 & 3 & 5 & 4 \\
\hline & Puntos agrupados & 1 & 1 & 4 & 2 & 5 & 3 \\
\hline & Áreas irreg. de puntos & 2 & 1 & 10 & 2 & 12 & 3 \\
\hline & Zigzag & 2 & 1 & 4 & 3 & 6 & 4 \\
\hline \multicolumn{2}{|c|}{ Sub-total Geométricos simples } & 14 & 3 & 79 & 14 & 93 & 17 \\
\hline \multirow{2}{*}{ Manos } & Negativo de manos & 50 & 6 & 552 & 21 & 602 & 27 \\
\hline & Positivos de manos & 5 & 1 & 4 & 3 & 9 & 4 \\
\hline \multicolumn{2}{|c|}{ Sub-total Manos } & 55 & 6 & 556 & 22 & 611 & 28 \\
\hline Pisadas & Tridígitos & 29 & 4 & 10 & 3 & 39 & 7 \\
\hline \multicolumn{2}{|c|}{ Sub-total Pisadas } & 29 & 4 & 10 & 3 & 39 & 7 \\
\hline Zoomorfos & Guanacos & 1 & 1 & 40 & 7 & 41 & 8 \\
\hline \multicolumn{2}{|c|}{ Sub-total Zoomorfos } & 1 & 1 & 40 & 7 & 41 & 8 \\
\hline \multirow{2}{*}{ Otros } & Arrastres individuales & 3 & 1 & 21 & 6 & 24 & 7 \\
\hline & Arrastres paralelos & 3 & 1 & 6 & 4 & 9 & 5 \\
\hline \multicolumn{2}{|c|}{ Sub-total Otros } & 6 & 1 & 27 & 6 & 35 & 7 \\
\hline \multicolumn{2}{|l|}{ Total general } & 105 & 7 & 712 & 26 & 817 & 33 \\
\hline
\end{tabular}

Tabla 1. Tipos de motivos compartidos entre LG y VQ ordenados por clases.

$=50=29,8 \%)$ y tridígitos $(\mathrm{N}=29=17,3 \%)^{5}($ ver Tabla 1$)$. Las técnicas utilizadas para la realización de los motivos incluyen - fundamentalmente- pintura en positivo $(\mathrm{N}=$ $72=42,8 \%)$ y pintura en negativo $(\mathrm{N}=50=29,8 \%)$. La frecuencia de motivos grabados en la localidad es escasa (grabado inciso: $\mathrm{N}=4=2,4 \%)^{6}$.

Viuda Quenzana (en adelante VQ), también comprende una superficie aproximada de 6 $\mathrm{km}^{2}$. Los relevamientos sistemáticos del arte rupestre de esta localidad se han focalizado en tres sectores, lindantes entre sí, con características geomorfológicas, altitudinales y litológicas diferentes (Figura 2B): a) Bardas Altas; b) Bardas Intermedias; y c) Cañadón Bajo (Fiore y Acevedo, 2016). Dado que la información proveniente de Cañadón Bajo se encuentra aún en etapas de procesamiento ( $c f$. Fiore y Acevedo, 2016), este trabajo se concentrará en el análisis de la producción rupestre de los sectores de Bardas Altas y Bardas Intermedias.

La producción rupestre de los sectores de bardas está compuesta por 26 sitios con arte: ocho en Bardas Altas (VQ1 a VQ6, VQ21 y VQ22) y 18 en Bardas Intermedias (VQ7 a VQ26 y VQ45) (Figura 2B). Dentro de estos sitios se registraron 1.105 motivos distribuidos entre 130 paneles. Estos motivos se agruparon en un repertorio de 71 TM, siendo los más frecuentes negativos de manos $(\mathrm{N}=552=49,9 \%)$, seguidos por: guanacos $(\mathrm{N}=40=3,6 \%)$, líneas rectas $(\mathrm{N}=32=2,9 \%)$, líneas sinuosas $(\mathrm{N}=30=$ $2,7 \%)$, líneas curvas $(\mathrm{N}=24=2,2 \%)$, circunferencias $(\mathrm{N}=24=2,2 \%)$, trazos cortos individuales por arrastre de dedos $(\mathrm{N}=21=1,9 \%)$, áreas irregulares de puntos $(\mathrm{N}$ $=10=0,9 \%)$ y tridígitos $(\mathrm{N}=10=0,9 \%)$ (ver Tabla 1$)$. Al igual que en el caso LG,
5. Los conteos de TM no incluyen manchas (LG: $\mathrm{N}=53=31,5 \%$; VQ: $\mathrm{N}=224=20,3 \%)$ por su falta de definición morfológica.

6. También se registró un número importante de manchas $(\mathrm{N}=42$ $=25 \%$ ) cuya variedad técnica no pudo ser identificada (pintura indeterminada) en virtud de su mal estado de conservación. 
7. Aquí también se registró un número importante de manchas $(\mathrm{N}=129=11,7 \%)$ cuya variedad técnica no pudo ser identificada (pintura indeterminada). el arte rupestre de VQ también es esencialmente pintado, incluyendo como técnicas principales la pintura en negativo $(\mathrm{N}=565=51,1 \%)$ y pintura en positivo $(\mathrm{N}=399$ $=36,1 \%)$. Las restantes técnicas de producción registradas exhiben frecuencias muy bajas, por ejemplo: pintura y grabado $(\mathrm{N}=5=0,4 \%)$, grabado inciso $(\mathrm{N}=4=0,4 \%)$, grabado inciso y piqueteado $(\mathrm{N}=1=0,1 \%)$ y pintura en positivo y pintura en negativo $(\mathrm{N}=2=0,2 \%)^{7}$.

\section{Reglas no-relacionales de composición visual: recurrencias y discontinuidades entre tipos de motivos compartidos por La Gruta y Viuda Quenzana}

El análisis comparativo de los repertorios morfológicos de LG (20 TM) y VQ (71 TM) muestra que ambas localidades comparten 14 TM en común: negativos de manos, positivos de manos, tridígitos, guanacos, almenados, líneas curvas, líneas sinuosas, meandros, óvalos, puntos agrupados, áreas irregulares de puntos, zigzags y arrastres de dedos individuales y paralelos (Tabla 1 y Figura 3). Estos TM incluyen los más frecuentes de cada localidad: negativos de manos y tridígitos en LG, y negativos de manos, guanacos, líneas curvas, líneas sinuosas, trazos cortos individuales por arrastre de dedos, áreas irregulares de puntos y tridígitos en VQ (Tabla 1 y Figura 3). Ahora bien, dado que LG posee un repertorio menos variado y VQ posee un repertorio más variado, el repertorio de LG está proporcionalmente más subsumido dentro del de VQ (LG: $\mathrm{N}=14=65 \%$ de $20 \mathrm{TM}$; VQ: $\mathrm{N}=14=18 \%$ de $71 \mathrm{TM}$ ), cuya producción visual es más diversa. Sin embargo, del total de 1.105 motivos $(\mathrm{NTM}=71)$ de VQ y 168 motivos $(\mathrm{NTM}=20)$ de LG, los 14 TM compartidos abarcan 712 motivos en la primera localidad y 105 en la segunda. Estos representan el 64,4\% de los motivos de VQ y el 62,5\% de los de LG, lo cual indica que, pese a tener una mayor variabilidad de repertorio, una gran proporción de la producción rupestre de VQ está orientada hacia tipos compartidos con LG, mientras que los restantes tipos del repertorio de VQ son realmente producciones poco frecuentes.

Estos resultados muestran que el vínculo entre LG y VQ, medido en términos de TM compartidos, no se ajusta a las expectativas planteadas para dos localidades cercanas potencialmente complementarias. En tal sentido, en virtud de las diferencias funcionales propuestas para cada localidad - residencial para VQ y logística para LG-, no se esperaba el mismo volumen de producción, lo cual se cumple claramente en el registro; pero sí se esperaba un mayor grado de vinculación morfológica entre los repertorios de sus sitios, lo cual se cumple parcialmente: de un repertorio total 76 TM, las dos localidades comparten solamente $14 \mathrm{TM}$, exhibiendo una mayor cantidad de TM no compartidos. En términos de la elección de diseños esto implica un grado comparativamente bajo de comunicación visual, principalmente en el caso de Viuda Quenzana donde predomina la producción de diseños independiente. Pero a su vez, sobre el total de 1.273 motivos, los 14 TM compartidos representan el $64,4 \%$ de la producción rupestre de VQ y el 62,5\% de LG, lo cual implica que los TM compartidos fueron los más enfatizados en la producción artística de cada localidad (Tabla 1). En este sentido, es posible sostener la existencia de un vínculo comunicacional centrado en esta porción del repertorio.

\section{Características técnicas de los tipos de motivos compartidos entre localidades}

El análisis de las técnicas de ejecución de los TM compartidos muestra que, con pocas excepciones, en ambas localidades se utilizaron las mismas técnicas para ejecutar los mismos TM: los negativos de manos se realizaron exclusivamente con pintura en negativo (LG: $\mathrm{N}=50=100 \%$; VQ: $\mathrm{N}=548=99,5 \%$ ) y los restantes TM (almenados, líneas curvas, líneas sinuosas, meandros, puntos agrupados, áreas irregulares de puntos, 

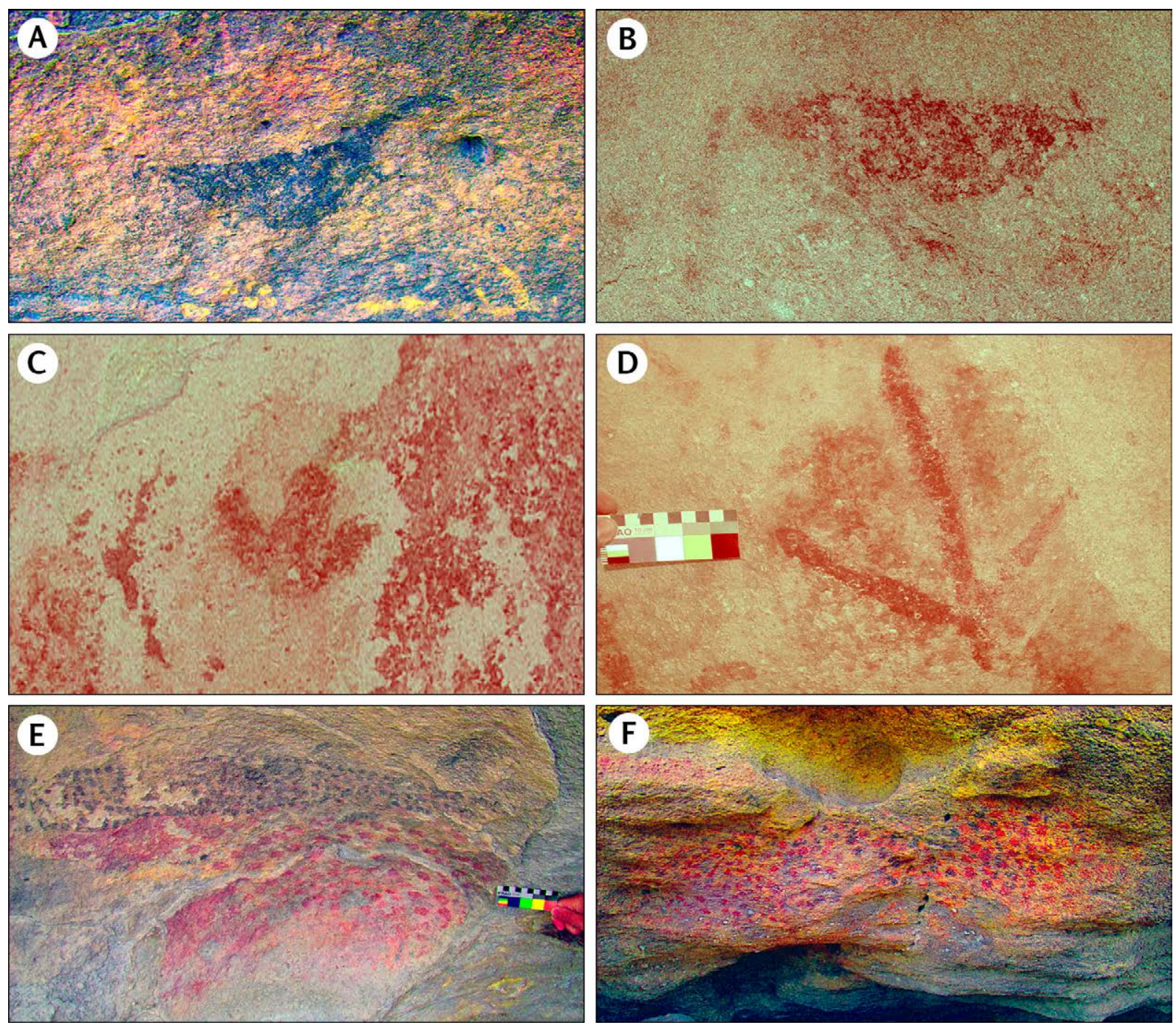

Figura 3. Ejemplos de tipos de motivos compartidos entre VQ y LG: A y B) guanacos en VQ y LG; $C$ y D) tridígitos en VQ y LG; Ey F) áreas irregulares de puntos en VQ y LG.

zigzag, positivos de manos, tridígitos, guanacos y, arrastre de dedos individuales y paralelos) principalmente con pintura en positivo (Figura 4A). Solo uno de los $14 \mathrm{TM}$ compartidos presenta diferentes técnicas en una y otra localidad: los óvalos, realizados con grabado inciso en $\mathrm{LG}(\mathrm{N}=2=100 \%)$ y con pintura en positivo en VQ $(\mathrm{N}=3=$ 100\%) (Figura 4A).

El análisis de los TM compartidos en función del modo de aplicación del trazo (continuo o discontinuo), también muestra similitudes entre ambas localidades, que utilizaron primordialmente las mismas técnicas, aplicadas del mismo modo, para los mismos TM (Figura 4B). Así:

a) la pintura en negativo aplicada en forma continua se reserva exclusivamente para los negativos de manos (LG: $\mathrm{N}=50=100 \%$; VQ: $\mathrm{N}=552=100 \%$ );

b) la pintura en positivo con trazo discontinuo para los puntos agrupados y áreas irregulares de puntos (LG: $\mathrm{N}=3=100 \%$; VQ: $\mathrm{N}=14=100 \%$ );

c) los restantes TM (tridígitos, positivos de manos, guanacos, almenados, líneas 


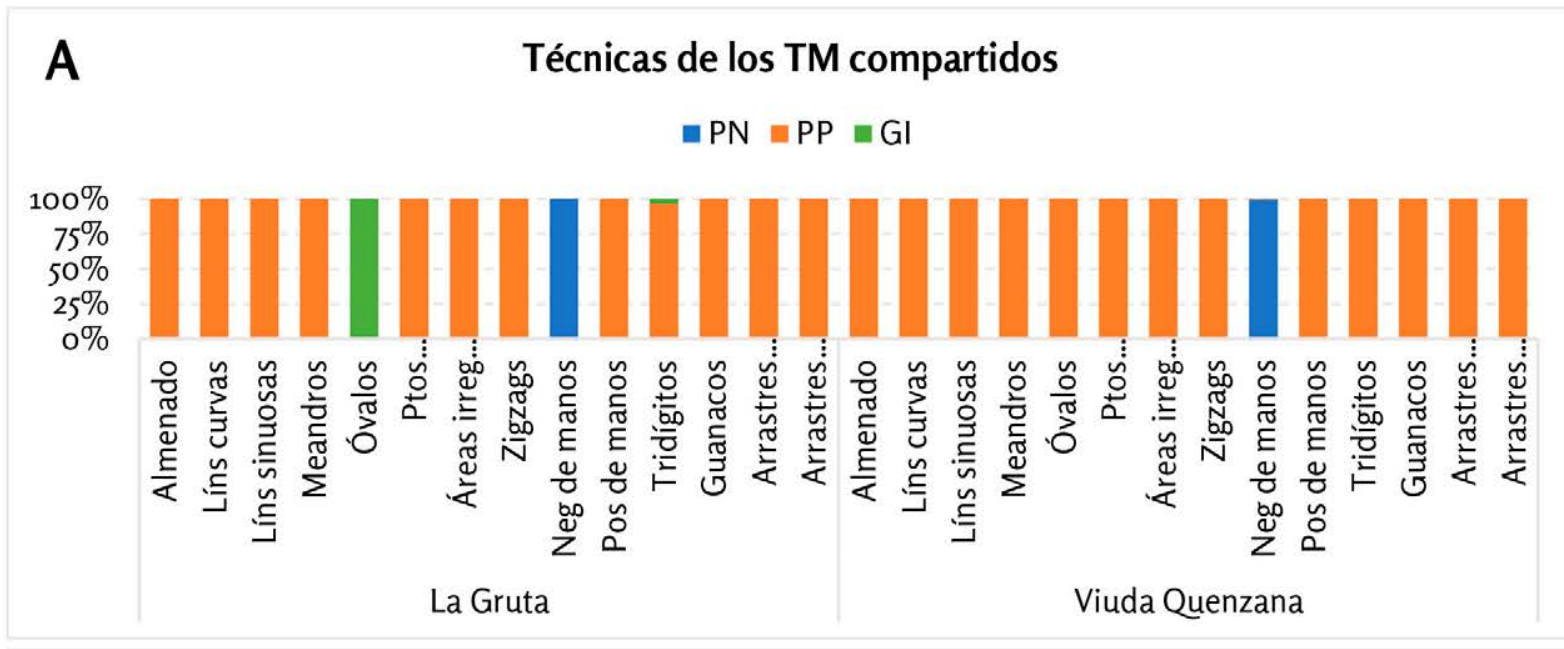

\section{B Modo de aplicación de las técnicas en los TM compartidos}

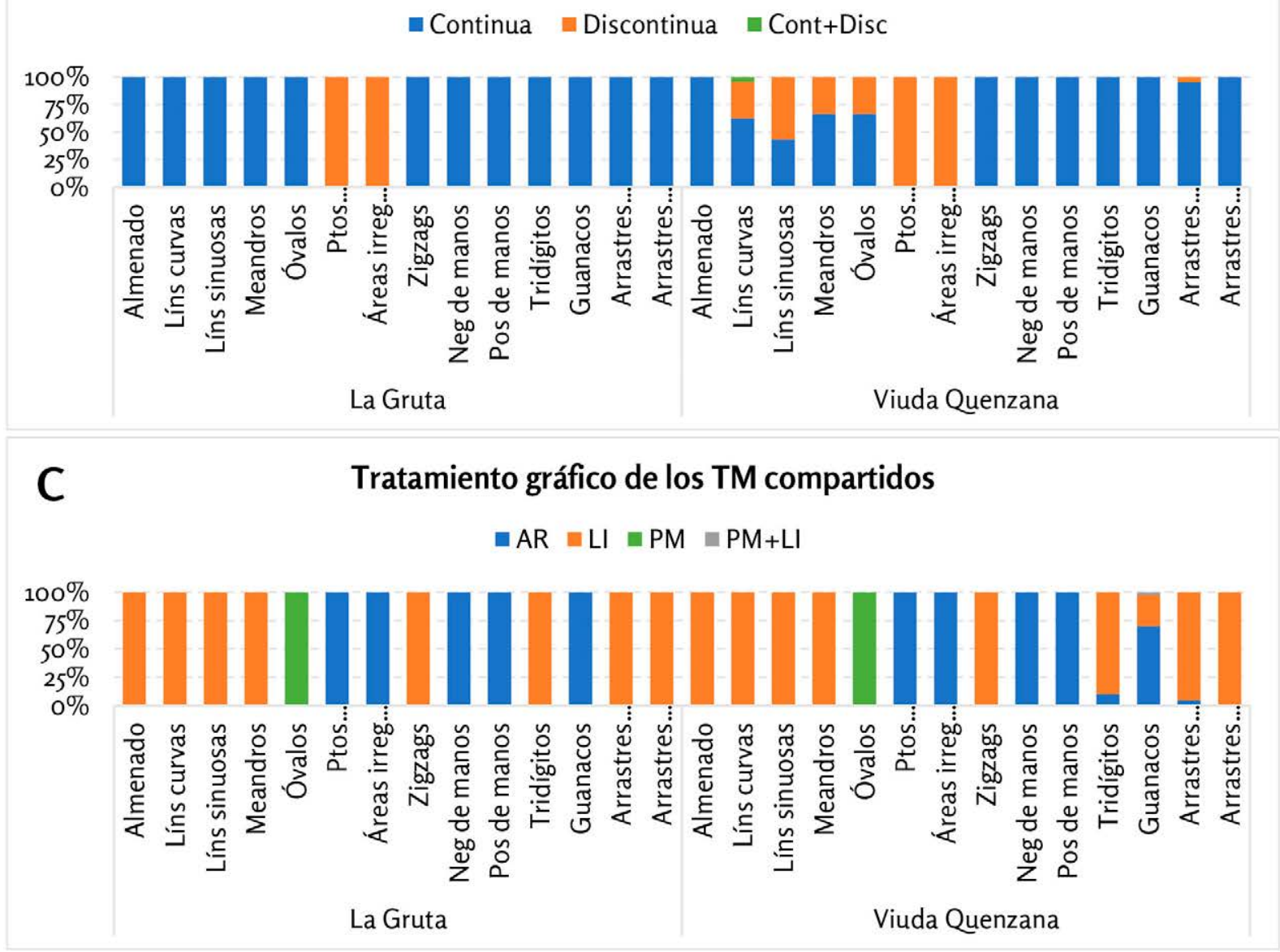

Figura 4. A) Técnicas de los tipos de motivos compartidos entre LG y VQ; B) Modo de aplicación de las técnicas en la ejecución de los tipos de motivos compartidos entre LG y VQ; C) Tratamiento gráfico de las formas de los tipos de motivos compartidos entre $L G$ y VQ. Referencias: $A R=$ areal; $L I=$ lineal; $P N=$ pintura en negativo; $P M=$ perimetral; $P P=$ pintura en positivo; $G I=$ grabado inciso.

curvas, meandros, zigzag y arrastres individuales y paralelos) fueron ejecutados mediante pintura en positivo y grabado inciso (en el caso de los óvalos) aplicadas mayoritariamente con trazo continuo $(\% \geq 50)$. 
La principal variabilidad en los modos de aplicación de los trazos se presenta entre los TM geométricos (líneas curvas, líneas sinuosas, meandros y óvalos), dentro de los cuales se observa mayor proporción de aplicación discontinua en VQ que en La Gruta (Figura 4B). Sin embargo, a pesar de esta variabilidad, en ambas localidades la forma de aplicación continua de los trazos pintados para la ejecución de estos TM es más recurrente $(\% \geq 50)$ que la discontinua. El único TM que exhibe diferencias en el modo de aplicación de la técnica en una y otra localidad es líneas sinuosas, ejecutadas - principalmente - mediante trazos discontinuos en VQ y mediante trazos continuos en LG (Figura 4B).

El análisis de los TM compartidos en función del tratamiento gráfico de sus formas, también muestra similitudes entre localidades (Figura 4C). En ambos casos:

a) los negativos y positivos de manos fueron construidos exclusivamente a partir de formas areales (LG: $\mathrm{N}=55=100 \%$; VQ: $\mathrm{N}=556=100 \%$ );

b) los tridígitos mediante formas lineales (LG: $\mathrm{N}=29=100 \%$; VQ: $\mathrm{N}=9=90 \%$ );

c) los guanacos mediante formas principalmente areales (LG: $N=1=100 \%$; VQ: $N$ $=28=70 \%)$;

d) los motivos geométricos mediante formas lineales (en el caso de los almenados, líneas curvas, líneas sinuosas, meandros y zigzag), areales (en el caso de los puntos agrupados y áreas irregulares de puntos) y perimetrales (en el caso de los óvalos); y,

e) los arrastres de dedos individuales y paralelos mediante formas lineales (LG: $\mathrm{N}=$ $6=100 \%$; VQ: $\mathrm{N}=26=96,3 \%)$.

En la mayoría de los casos, con excepción de los geométricos (d), el tratamiento gráfico elegido es esperable debido a la morfología de base de cada motivo, que implica una construcción plástica específicamente areal o lineal de la forma del motivo. En el caso de los geométricos (d), los manejos del tratamiento gráfico de las formas tienen mayor elasticidad de opciones y por lo tanto demuestran —un poco más- elecciones de los productores, que no se ciñen necesariamente a requerimientos de la morfología de cada tipo de motivo en particular.

Para finalizar, el análisis de los colores de los TM compartidos también muestra similitudes, ya que en ambas localidades se observa un predominio de colores rojizos para la ejecución de los TM compartidos. Si bien, en términos específicos, se puede apreciar la existencia de diferencias de tonalidades para los mismos TM en LG y VQ, todas estas tonalidades corresponden a distintitas variaciones del color rojo ${ }^{8}$. Estos resultados, son consistentes con las tendencias generales obtenidas para las producciones rupestres de ambos espacios en cuanto a la preferencia por la utilización de colores rojizos para la realización de la mayoría de las imágenes (LG: $\mathrm{N}=150=$ 94,3\%; VQ: $\mathrm{N}=883=81 \%)^{9}$. Sugerimos que estas preferencias tienen como base una oferta potencial mucho mayor de pigmentos con tonos rojizos en la localidad de VQ, respecto de otros colores disponibles localmente.

En síntesis, los resultados expuestos hasta el momento permiten observar la presencia de recurrencias entre los TM compartidos por ambas localidades visibles en:

a) a utilización de pintura en negativo, de colores rojizos, aplicada en forma continua y con tratamiento gráfico areal para la construcción de negativos de manos;

b) la utilización de pintura en positivo, de colores rojizos, aplicada en forma:
8. Variaciones del color rojo registradas entre los TM compartidos (el nombre de los colores es una traducción de la nomenclatura utilizada en la escala Munsell, 1994): Amarillo rojizo (reddish yellow:7.5YR/6/8); Rojo (red: $10 R / 4 / 6,10 R / 4 / 8,10 R / 5 / 6$, $10 R / 5 / 8$ ); Rojo claro (light red: $10 R / 6 / 6,10 R / 6 / 8,10 R / 7 / 6,10 R / 7 / 8$, $2.5 \mathrm{YR} / 6 / 6,2.5 \mathrm{YR} / 6 / 8,2.5 \mathrm{YR} / 7 / 6$, 2.5 $\mathrm{YR} / 7 / 8$ ); Rojo suave (weak red: $10 \mathrm{R} / 4 / 2,10 \mathrm{R} / 4 / 3,10 \mathrm{R} / 4 / 4,10 \mathrm{R} / 5 / 2$, $10 \mathrm{R} / 5 / 3,10 \mathrm{R} / 5 / 4$ ); Rojo pálido (pale red: $10 \mathrm{R} / 6 / 2,10 \mathrm{R} / 6 / 3,10 \mathrm{R} / 6 / 4$, $10 R / 7 / 3,10 R / 7 / 4$ ); Rojo oscuro (dark red: $10 \mathrm{R} / 3 / 6,2.5 \mathrm{YR} / 3 / 6)$; Rosado (pink: 10R/8/4).

9. El cálculo de los porcentajes está realizado sobre el total de casos en que se pudo registrar el color en cada localidad (LG: N = 159 de 168 motivos; VQ: $\mathrm{N}=1.090$ de 1.105 motivos). 
10. Las direcciones de las áreas irregulares de puntos se definieron a partir del eje de extensión máxima del motivo. i) continua y areal para la construcción de positivos de manos y guanacos;

ii) continua y lineal para la construcción de tridígitos, almenados, líneas curvas, meandros, zigzags y arrastres de dedos individuales y paralelos;

iii) discontinua y areal para la construcción de puntos agrupados y áreas irregulares de puntos.

Estas semejanzas en las técnicas de ejecución, los modos de aplicación de trazos, el tratamiento gráfico de las formas y los colores utilizados permiten pensar en la existencia de pautas de producción similares entre los TM compartidos por ambas localidades.

\section{Dirección de los tipos de motivos compartidos entre localidades}

El análisis de las direcciones de los TM compartidos entre LG y VQ muestra más diferencias que similitudes entre localidades. En este sentido, se observa que:

a) sólo cuatro de los $14 \mathrm{TM}$ compartidos se direccionan de forma similar (vertical) en ambas (negativos de manos, tridígitos, áreas irregulares de puntos ${ }^{10} \mathrm{y}$ meandros);

b) un TM (líneas sinuosas) se direcciona parcialmente similar (horizontal en LG; horizontal y diagonal derecha arriba en VQ); y,

c) nueve TM se direccionan de manera diferente en una otra localidad.

Ahora bien, las similitudes de direccionamiento existentes entre algunos TM compartidos por LG y VQ no cumplen con los requisitos de frecuencia y porcentaje ( $\mathrm{f}$ $\geq 5 ; \% \geq 50$ ) definidos como necesarios para hablar de reglas de dirección. Sólo tres TM tienen la suficiente cantidad de casos para permitir sostener la presencia de reglas de dirección y todos corresponden a VQ: guanacos direccionados frecuentemente en forma horizontal hacia la derecha $(\mathrm{N}=26=65 \%)$, tridígitos direccionados frecuentemente en forma en vertical $(\mathrm{N}=6=60 \%)$ y negativos de manos direccionados frecuentemente en forma vertical $(\mathrm{N}=275=50 \%)$. En el caso de $L G$, los negativos de manos exhiben una tendencia significativa de direccionamiento vertical $(\mathrm{N}=22=44 \%)$, pero que no alcanza para hablar de "regla" en los términos definidos en este trabajo.

En virtud de lo expuesto, es posible sostener que las pautas de producción compartidas, previamente señaladas, entre los TM presentes en LG y VQ no se extienden sobre su direccionalidad, cuya variabilidad intra e inter-localidad y bajas frecuencias y/o porcentajes de adhesión no permiten sostener la existencia de reglas de dirección compartidas entre localidades.

Atributos de los soportes rocosos seleccionados para el emplazamiento de los tipos de motivos compartidos entre ambas localidades

En este acápite se analizan los atributos de los soportes rocosos seleccionados para el emplazamiento de los 14 TM compartidos entre LG y VQ, incluyendo la elección de: orientaciones, microtopografías, superficies generales y ángulos de inclinación de los soportes utilizados.

El análisis de las orientaciones generales de los soportes en que se encuentran emplazados los TM compartidos entre LG y VQ muestra que: 
a) sólo dos de los $14 \mathrm{TM}$ compartidos orientan del mismo modo (negativos de manos al norte y almenados al oeste);

b) un TM (líneas curvas) orienta parcialmente del mismo modo (hacia abajo y hacia el norte en LG; hacia el norte en VQ); y,

c) $11 \mathrm{TM}$ se orientan de manera diferente en una y otra localidad (Tabla 2).

De los dos TM compartidos que presentan orientaciones similares (negativos de manos y almenados), sólo en el caso de los negativos de manos es posible sostener la existencia de una regla de orientación (hacia el norte), compartida entre LG y VQ, a partir de sus frecuencias y porcentajes (LG: $\mathrm{N}=27=54 \%$ y en VQ: $\mathrm{N}=347=62,9 \%$ ). Otros TM presentan reglas de orientación diferentes entre ambas (e.g. los tridígitos: hacia abajo en LG: $\mathrm{N}=24=82,7 \%$ y hacia el sur en VQ: $\mathrm{N}=7=70 \%$ ), o presentan reglas solo en una localidad y no en la otra (e.g. guanacos, áreas irregulares de puntos y arrastres individuales en VQ) (Tabla 2).

El análisis de los rasgos microtopográficos seleccionados para el emplazamiento de los TM compartidos entre LG y VQ (Figura 5A) muestra que no existe ningún caso en que los mismos TM se ubiquen sobre una misma microtopografía en una y otra localidad. En términos de reglas, sólo en dos TM se puede sostener la existencia de comportamientos reglados $(\mathrm{f} \geq 5 ; \% \geq 50)$ en la selección de rasgos microtopográficos: tridígitos de $\mathrm{LG}$, frecuentemente ubicados sobre reparos $(\mathrm{N}=25=86,2 \%)$, y arrastres individuales de dedos de VQ ubicados sobre nichos $(\mathrm{N}=14=66,6 \%)$. Por todo ello, en términos de selección de microtopografías, no se observan reglas compartidas.

El análisis de las superficies generales de los soportes seleccionados para el emplazamiento de los TM compartidos entre ambas localidades (Figura 5B) muestra que:

a) sólo dos de los $14 \mathrm{TM}$ en común se ubican frecuentemente sobre el mismo tipo de superficie de soporte (tridígitos y almenados sobre soporte planos);

b) cinco TM se sitúan parcialmente sobre soportes de superficies similares (e.g. guanacos sobre superficies planas en LG y sobre superficies planas y cóncavas en VQ); y,

c) siete TM se sitúan frecuentemente sobre soportes de superficies diferentes (Tabla $3)$.

De los dos TM compartidos que presentan superficies similares en una y otra localidad, sólo en el caso de los tridígitos es posible sostener la existencia de una regla de selección de superficies de soportes (planos) compartida (LG: $\mathrm{N}=28=96,5 \%$; VQ: $\mathrm{N}=6=$ $60 \%)$. En los restantes TM, se observa la presencia de reglas de selección de soporte no compartidas, sino presentes en cada localidad (Tabla 3). En el caso de LG, los negativos de manos emplazados sobre superficies planas $(\mathrm{N}=30=60 \%)$. En VQ, las áreas irregulares de puntos (emplazadas sobre superficies cóncavas: $\mathrm{N}=9=90 \%$ ), las líneas curvas (emplazadas sobre superficies cóncavas $(\mathrm{N}=14=58,3 \%)$ y los arrastres individuales (emplazados sobre superficies cóncavas: $\mathrm{N}=15=71,4 \%$ ). Por lo tanto, sólo en el caso de los tridígitos es posible hablar de reglas de selección de superficies del soporte semejantes en ambas localidades (Tabla 3 ).

Por último, el análisis de los ángulos de inclinación de los soportes rocosos seleccionados para el emplazamiento de los TM compartidos entre LG y VQ (Figura 5C) muestra que, de los 14 TM compartidos: 


\begin{tabular}{|c|c|c|c|c|c|c|c|c|c|}
\hline \multirow{2}{*}{ TM compartidos } & \multicolumn{6}{|c|}{ LG } & \multicolumn{3}{|c|}{ VQ } \\
\hline & \multicolumn{2}{|c|}{ OG } & \multicolumn{2}{|c|}{$f$} & \multicolumn{2}{|c|}{$\%$} & OG & $f$ & $\%$ \\
\hline Almenados & \multicolumn{2}{|c|}{ W } & \multicolumn{2}{|c|}{2} & \multicolumn{2}{|c|}{100} & W & 1 & 100 \\
\hline Líneas curvas & & $\mathrm{N}$ & 1 & 1 & & 50 & $\mathrm{~N}$ & 12 & 50 \\
\hline Líneas sinuosas & \multicolumn{2}{|c|}{ W } & \multicolumn{2}{|c|}{1} & \multicolumn{2}{|c|}{100} & S & 10 & 33,3 \\
\hline Meandros & \multicolumn{2}{|c|}{ W } & \multicolumn{2}{|c|}{2} & \multicolumn{2}{|c|}{100} & $M x$ & 1 & 33,3 \\
\hline Óvalos & \multicolumn{2}{|c|}{ Ar } & \multicolumn{2}{|c|}{2} & \multicolumn{2}{|c|}{100} & $\mathrm{~N}$ & 2 & 66,7 \\
\hline Puntos agrupados & \multicolumn{2}{|c|}{$\mathrm{Ab}$} & \multicolumn{2}{|c|}{1} & \multicolumn{2}{|c|}{100} & $N$ & 3 & 65 \\
\hline Áreas irreg. de puntos & \multicolumn{2}{|c|}{$\mathrm{Ab}$} & & & \multicolumn{2}{|c|}{100} & $N$ & 9 & 90 \\
\hline Zigzag & & W & 1 & 1 & 50 & 50 & $S$ & 3 & 75 \\
\hline Negativo de manos & \multicolumn{2}{|c|}{$\mathrm{N}$} & \multicolumn{2}{|c|}{27} & \multicolumn{2}{|c|}{54} & $\mathrm{~N}$ & 347 & 62,9 \\
\hline Positivos de manos & \multicolumn{2}{|c|}{$\mathrm{N}$} & \multicolumn{2}{|c|}{4} & \multicolumn{2}{|c|}{80} & S & 2 & 50 \\
\hline Tridígitos & \multicolumn{2}{|c|}{$\mathrm{Ab}$} & \multicolumn{2}{|c|}{24} & \multicolumn{2}{|c|}{82,7} & S & 7 & 70 \\
\hline Guanacos & \multicolumn{2}{|c|}{$\mathrm{Ab}$} & \multicolumn{2}{|c|}{1} & \multicolumn{2}{|c|}{100} & $\mathrm{~N}$ & 32 & 80 \\
\hline Arrastres individuales & \multicolumn{2}{|c|}{ W } & & & & & $N$ & 14 & 66,7 \\
\hline Arrastres paralelos & & & & & & & $N$ & 3 & 50 \\
\hline
\end{tabular}

Tabla 2. Orientaciones generales más frecuentes de los TM compartidos entre LG y VQ. Referencias: $N=$ Norte; $S=S u r ; W=$ Oeste; $A b=$ Abajo; Ar = Arriba; $M x=$ Mixta (p. ej. $A b+N)$.

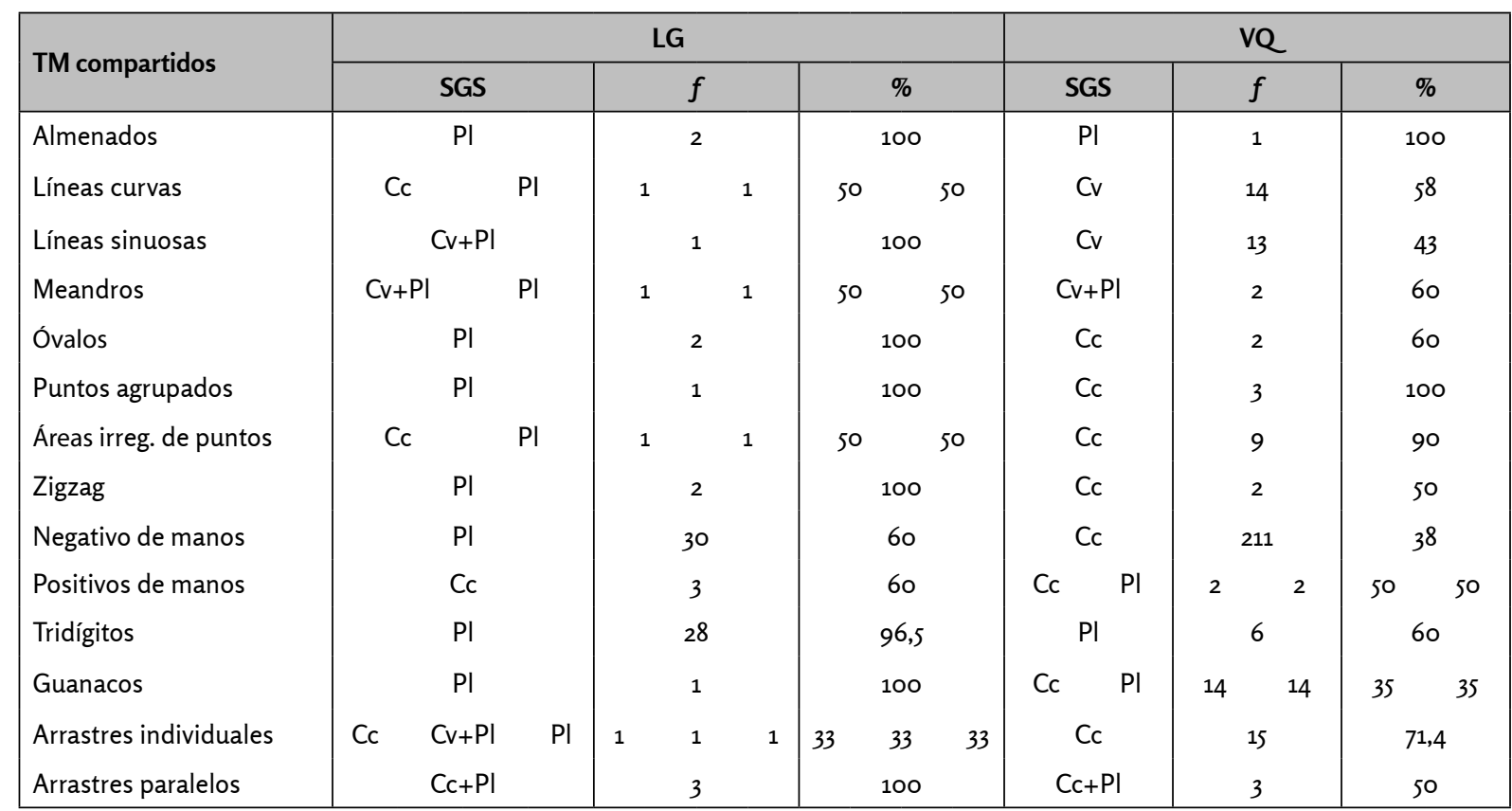

Tabla 3. Superficie general de los soportes utilizados para emplazar los TM compartidos entre LG y VQ. Referencias: PI = Plano; CC = Cóncavo; $\mathrm{Cv}=$ Convexo.

a) cuatro TM se ubican frecuentemente sobre soportes inclinados en ángulos similares (almenados en ángulos verticales; líneas sinuosas y arrastres de dedos paralelos en ángulos agudos; meandros en combinaciones de ángulos agudos + verticales);

b) cuatro TM se sitúan parcialmente sobre soportes con los mismos ángulos de inclinación (líneas curvas sobre ángulos agudos y horizontales en LG y agudos 


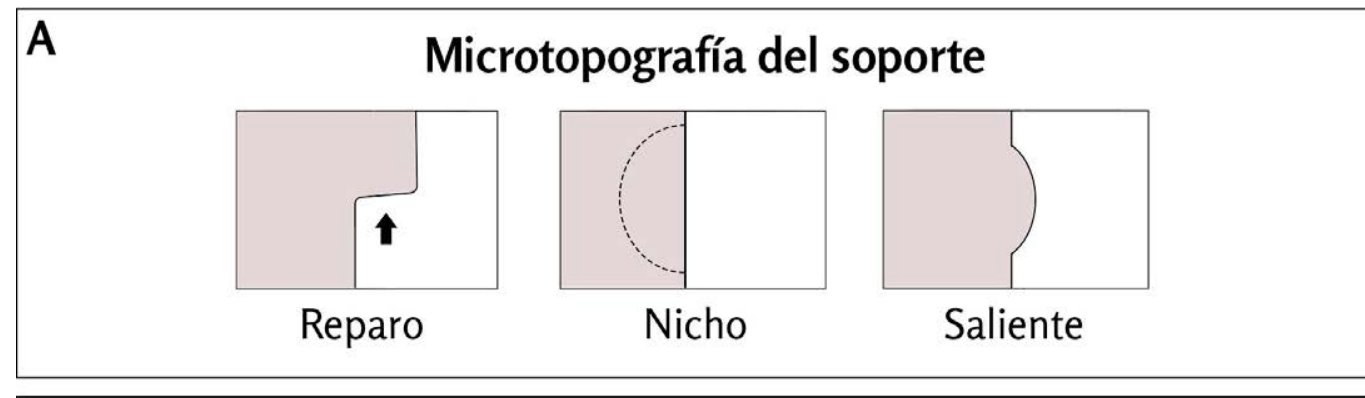

\section{B}

\section{Superficie general del soporte}

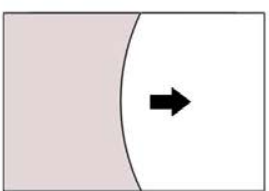

Cóncava

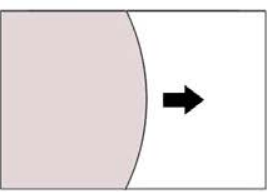

Convexa

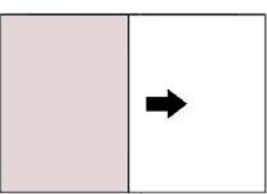

Plana
C

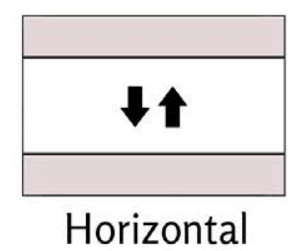

Ángulo respecto del suelo

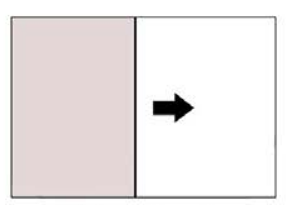

Vertical

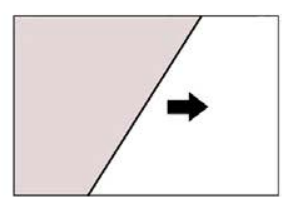

Agudo

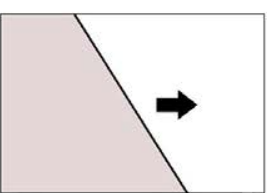

Obtuso

Figura 5. Atributos de los soportes rocosos seleccionados para el emplazamiento de los tipos de motivos compartidos.

\begin{tabular}{|c|c|c|c|c|c|c|c|c|c|c|}
\hline \multirow{2}{*}{ TM compartidos } & \multicolumn{5}{|c|}{ LG } & \multicolumn{5}{|c|}{ VQ } \\
\hline & ARS & \multicolumn{2}{|c|}{$f$} & \multicolumn{2}{|c|}{$\%$} & ARS & \multicolumn{2}{|c|}{$f$} & \multicolumn{2}{|c|}{$\%$} \\
\hline Almenados & V & \multicolumn{2}{|c|}{2} & \multicolumn{2}{|c|}{100} & V & \multicolumn{2}{|c|}{1} & \multicolumn{2}{|c|}{100} \\
\hline Líneas curvas & Ic1 & 1 & 1 & 50 & 50 & Ic1 I $1+\mathrm{V}$ & 9 & 9 & 37,5 & 37,5 \\
\hline Líneas sinuosas & Ic1 & \multicolumn{2}{|c|}{1} & \multicolumn{2}{|c|}{100} & Ic1 & & & & 7 \\
\hline Meandros & lc1 & 1 & 1 & 50 & 50 & $\mathrm{I} 1+\mathrm{V}$ & & & & o \\
\hline Óvalos & Ic2 & \multicolumn{2}{|c|}{2} & \multicolumn{2}{|c|}{100} & $\mathrm{Ic} 1+\mathrm{V}$ & & & & o \\
\hline Puntos agrupados & $\mathrm{H}$ & \multicolumn{2}{|c|}{1} & \multicolumn{2}{|c|}{100} & Ic1 & & & & 5 \\
\hline Áreas irreg. de puntos & $\mathrm{I}_{\mathrm{c} 1}$ & 1 & 1 & 50 & 50 & $\mathrm{H}+\mathrm{lc} 1+\mathrm{V}$ & & & & o \\
\hline Zigzag & $\mathrm{H}+\mathrm{Ic}_{\mathrm{c}} \quad \mathrm{V}$ & 1 & 1 & 50 & 50 & Ic1 & & & & 5 \\
\hline Negativo de manos & $\mathrm{Ic} 1$ & \multicolumn{2}{|c|}{18} & \multicolumn{2}{|c|}{36} & $\mathrm{Ic} 1+\mathrm{V}$ & & & & \\
\hline Positivos de manos & lc1 & \multicolumn{2}{|c|}{3} & \multicolumn{2}{|c|}{60} & V & & & & 15 \\
\hline Tridígitos & $\mathrm{H}$ & \multicolumn{2}{|c|}{19} & \multicolumn{2}{|c|}{65,5} & $\mathrm{Ic} 1$ & & & & 15 \\
\hline Guanacos & $\mathrm{H}$ & \multicolumn{2}{|c|}{1} & \multicolumn{2}{|c|}{100} & Ic1 & & & & 7,5 \\
\hline Arrastres individuales & Ic1 & & & & & $\mathrm{Ic} 1+\mathrm{V}$ & & & & 7,1 \\
\hline Arrastres paralelos & Ic1 & & & & & Ic1 & & & & o \\
\hline
\end{tabular}

Tabla 4. Ángulos de inclinación de los soportes utilizados para emplazar los TM compartidos entre LG y VQ. Referencias: $H=H o r i z o n t a l ; ~ V=$ Vertical; Ic1 = Agudo; Ic2 = Obtuso. 
y agudos + verticales en VQ; negativos de manos y arrastres individuales sobre ángulos agudos en LG y agudos + verticales en VQ; y zigzags sobre ángulos horizontales y agudos + verticales en LG y agudos en VQ); $y$,

c) seis TM se ubican frecuentemente sobre soportes con distinto ángulo de inclinación en una y otra localidad (Tabla 4).

Ahora bien, ninguno de los cuatro TM que se encuentran frecuentemente ubicados sobre soportes con el mismo ángulo de inclinación en una y otra localidad presenta frecuencias y/o porcentajes suficientes para sostener la presencia de reglas de composición visual (Tabla 4). Los únicos TM que exhiben reglas en la selección de los ángulos de inclinación de los soportes muestran inclinaciones diferentes y/o ausencia de contrapartes en la otra localidad. En el caso de LG, los tridígitos se emplazan sobre soportes inclinados en ángulos agudos $(\mathrm{N}=19=65,6 \%)$. En el caso de $\mathrm{VQ}$, las líneas sinuosas se ubican sobre soportes inclinados en ángulos agudos $(\mathrm{N}=17=56,7 \%)$ y los arrastres de dedos individuales sobre inclinaciones agudas + verticales $(\mathrm{N}=12$ $=57,1 \%)$. Estos resultados permiten observar la ausencia de reglas de inclinación semejantes entre los TM compartidos por LG y VQ (Tabla 4).

En síntesis, los resultados obtenidos muestran que no hay ningún TM compartido entre LG y VQ que se ubique, en ambas localidades, sobre soportes con la misma orientación, microtopografía, superficie general y ángulo de inclinación respecto del suelo. Hay TM que comparten similitudes, pero sólo en la selección de algún/os atributo/s de los soportes, nunca en su totalidad.

\section{Síntesis de resultados}

Los análisis realizados permiten arribar a diferentes conclusiones respecto de las relaciones existentes entre TM y soportes:

1) No todos los TM compartidos exhiben reglas en la selección de atributos de los soportes en ambas localidades:

a. en el caso de LG, sólo lo hacen dos de los 14 TM compartidos: negativos de manos y tridígitos;

b. en el caso de VQ, siete de los 14 TM compartidos: líneas curvas y sinuosas, áreas irregulares de puntos, negativos de manos, tridígitos, guanacos y arrastres individuales.

2) La mayoría de los TM compartidos presentan "reglas" de selección sobre uno o dos atributos del soporte (generalmente orientación y superficie general). Sólo en dos casos se observa la presencia de conjuntos o cuerpos de reglas de selección de soportes:

a. los tridígitos en LG, emplazados sobre reparos de superficie plana, orientados hacia abajo e inclinados en ángulos horizontales;

b. los arrastres de dedos individuales en VQ, emplazados sobre nichos de superficie cóncava, orientados hacia el norte e inclinados en ángulos verticales-agudos.

3) Sólo dos de los 14 TM compartidos entre ambas localidades exhiben reglas similares de selección de soportes:

a. los negativos de manos orientados frecuentemente hacia el norte; 
b. los tridígitos emplazados principalmente sobre soportes planos.

Estos resultados muestran una baja frecuencia de reglas de selección de soportes en los TM compartidos entre ambas localidades. Estas reglas - mayoritariamente- no se presentan como un cuerpo sistemático de pautas que actúan sobre la elección del conjunto de las características del soporte, sino que operan irregularmente sobre la selección de algunos atributos y no de otros, implicando un bajo grado de recurrencias a la hora de escoger los soportes rocosos que serán utilizados para el emplazamiento de los TM.

\section{Discusión y conclusiones: de comunicación, estética y grados de libertad creativa}

Los resultados presentados y analizados en este trabajo muestran similitudes entre las producciones rupestres de La Gruta y Viuda Quenzana en términos de: a) los 14 TM compartidos; b) realizados con las mismas técnicas; c) aplicadas del mismo modo; d) utilizando los mismos colores; y, e) con el mismo tratamiento gráfico de las formas.

Estas similitudes invitan a pensar en la existencia de pautas subyacentes de producción de imágenes compartidas entre localidades. Sin embargo, dichas pautas no se registran en variables tales como:

a) el direccionamiento de los TM compartidos: la mayoría de ellos presentan direcciones diferentes y sólo existen reglas de dirección en tres TM de una misma localidad (guanacos, tridígitos y negativos de manos en VQ);

b) la selección de emplazamientos de los TM compartidos: sólo dos de los 14 TM registraron comportamientos reglados semejantes en una y otra localidad (los negativos de manos emplazados sobre soportes orientados hacia el norte y los tridígitos emplazados sobre soportes planos).

En función de lo expuesto, es posible señalar la presencia de pautas de producción compartidas entre LG y VQ vinculadas con las reglas no-relacionales de composición que operaron sobre los aspectos formales y técnicos de los motivos, pero no así con las reglas que operaron sobre el direccionamiento de las imágenes y sus vínculos con el soporte. Estas últimas exhiben un bajo grado de recurrencia y, por lo tanto, de control social sobre las prácticas de producción artística en ambas localidades (es decir, una mayor libertad de acción), lo cual es coherente con contextos socioculturales más laxos como los que se asumen para las sociedades cazadoras-recolectoras analizadas en este trabajo (Bird y O'Connell, 2006; Lee y Daly, 2002; Morgan, Tushingham, Garvey, Barton y Bettinger, 2017). Todo ello permite inferir la existencia de un grado básico de comunicación visual entre ambas localidades, pero no permite verificar la presencia de un sistema completo de reglas no-relacionales de composición visual, en los términos definidos en este trabajo.

Es posible que esto esté relacionado con los requerimientos básicos del proceso de comunicación visual. Las imágenes participantes de un sistema de comunicación requieren cierto grado de estandarización que permita la codificación formal de información - en la producción - y su decodificación —en la visualización- (Basile, 2012; Giraudo y Martel, 2015; Fiore, 2006; Llamazares, 1986, 1992; entre otros). Dicha estandarización implica recurrencias en la producción de motivos, que pueden darse en diferentes niveles y de forma acumulativa, por ejemplo: la repetición de una morfología (tipo de motivo), la repetición de una misma morfología ejecutada siempre con una misma técnica, o en una misma dirección, o en un mismo color, o emplazada siempre 
en soportes de las mismas características, o la combinación de algunas o todas estas variables (Fiore, 2006).

Los niveles básicos de estandarización identificados entre LG y VQ invitan a pensar que, quizás, la comunicación visual de las poblaciones cazadoras-recolectoras que habitaron estas localidades no requirió de parámetros de codificación de información tan estrictos como los planteados en el marco teórico de este trabajo. Cabe la posibilidad de que el vínculo entre las imágenes rupestres y sus referentes haya sido tan directo (Eco, 2013) que no haya necesitado de la articulación sistemática de un motivo con una dirección determinada, o con un soporte de características específicas, para la codificación y decodificación de información, sino simplemente de la adhesión a un conjunto de reglas estéticas (sensu Wobst, 1977) actuantes sobre la morfología, la técnica y los colores de los motivos. Prescindir de un código visual estricto, o no adherirse enteramente a él, pudo haber sido más efectivo para la comunicación visual diacrónica entre grupos cazadores-recolectores. Asimismo, el hecho de que la comunicación mediante imágenes rupestres no haya estado estrictamente estructurada según las expectativas teóricas aquí planteadas, invita a reflexionar sobre la posibilidad de que el propio proceso de producción - desde la selección de materias primas hasta la ejecución técnica de los motivos - haya constituido una parte fundamental de la importancia social de las imágenes (Fiore, 1996, 2009). Por último, tampoco se puede descartar la posibilidad de que las recurrencias hayan respondido a cuestiones de índole estética más que $-\mathrm{o}$ además de-cuestiones de índole informativa. Esto es interesante porque las cualidades morfológicas y técnicas constituyen atributos perceptibles de manera visual-sensorial, enfatizando su potencialidad estética. En función de ello, resulta ineludible remarcar la potencial equifinalidad - comunicativa y estética - de estos atributos de los motivos rupestres analizados y la necesidad de seguir profundizando su estudio.

Una posible explicación de las diferencias observadas entre las producciones rupestres de LG y VQ surge de su comparación con las producciones rupestres de sitios y localidades vecinas (e.g. La Martita, Guanaquitos, Alero Quebrada Colorada, Alero Campo Corral, El Verano, La María y El Ceibo), las cuales comparten más similitudes con VQ, que con LG (e.g. producciones realizadas en una amplia paleta de colores, dominadas por conjuntos de negativos de manos, con presencia importante de representaciones de guanacos y de conjuntos de guanacos, a los que se suman motivos geométricos puntiformes $y$, en forma menos frecuente, negativos de pie, de pata de choique, antropomorfos y motivos geométricos complejos, entre otros, emplazados en paisajes y soportes de topografías semejantes (cf. Cardich, 1979, 1987; Durán, 19831985; Franchomme, 1987; Gradin y Aguerre, 1983; Paunero, 2009; Paunero et al., 2005, Figura 6 y 7$)$.

Frente a este escenario se propone, como una inferencia a escala supra-regional, que los bajos niveles de comunicación visual existentes entre ambas localidades, podrían responder a diferencias en cuanto a sus formas de integración dentro de circuitos más grandes de movilidad e intercambio de información entre poblaciones cazadorasrecolectoras. En este sentido, se plantea como posibilidad que:

1) VQ haya formado parte integral de un circuito de movilidad con ejes:

a) norte-sur, constituido por los cañadones ubicados al norte de la localidad que desembocan en el río Seco y, en última instancia, en el Guadal de Baqueró (incluyendo localidades como La Martita, Guanaquitos y sitios como Alero Quebrada Colorada, Alero Campo Corral, al norte y localidades como El Verano, al sur, sobre el Guadal de Baqueró) (Figura 8); y,

b) este-oeste incluyendo localidades como La María y El Ceibo (Cardich, 1979, 1987; 

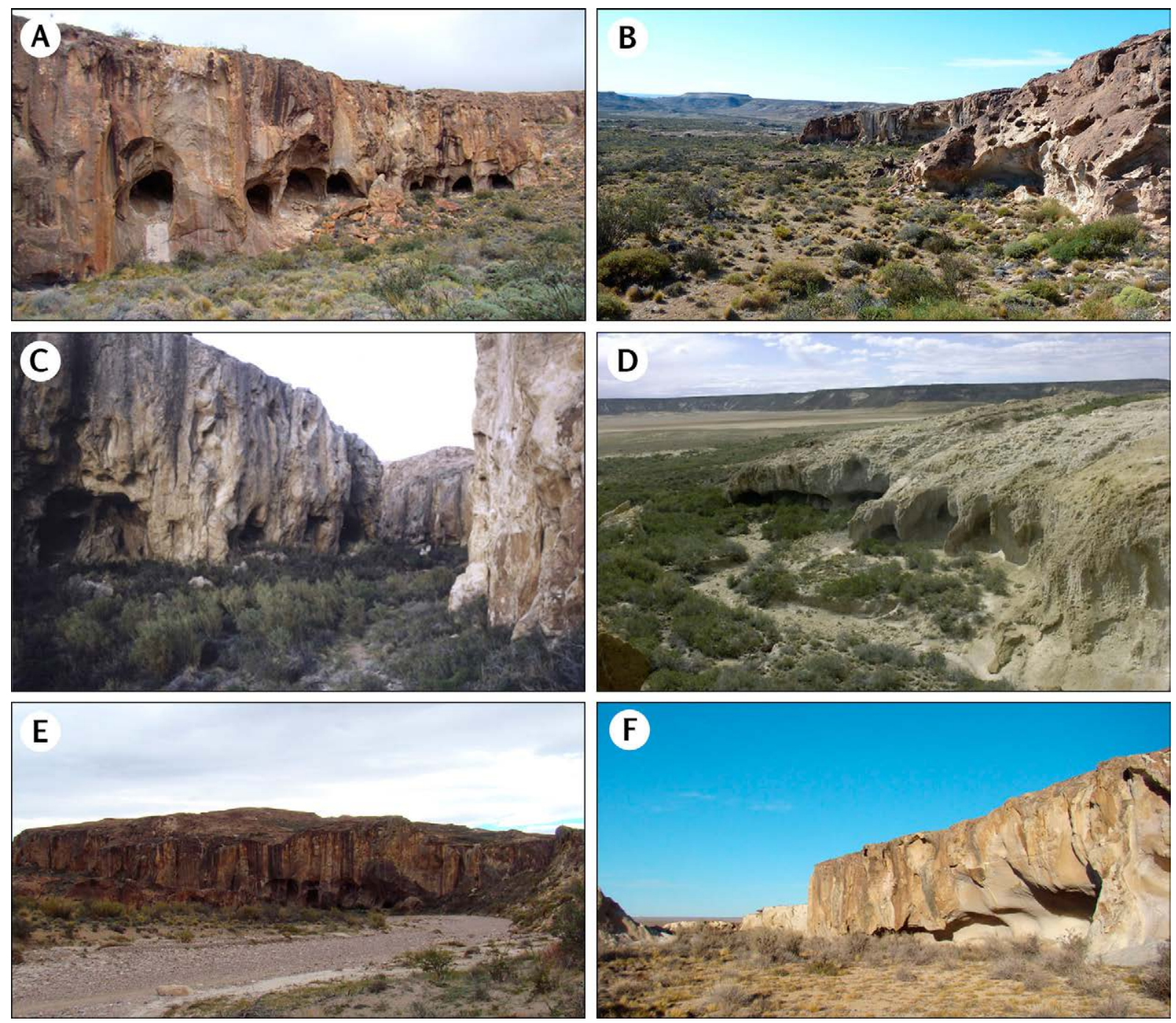

Figura 6. Similitudes topográficas entre VQ y localidades vecinas: A y B) VQ Cañadón y Bardas; C y D) La María Quebrada y Bajo (Paunero, 2009, figura 9 y 10); E) Cañadón de La Martita; F) Bardas de El Verano.

Durán, 1983-1985; Gradin y Aguerre, 1983; Paunero, 2009; Paunero et al., 2005) (Figura 8).

2) LG, ubicada más al sur - sobre las estribaciones meridionales de Macizo del Deseado-, haya participado de forma más periférica (o marginal) en dicho circuito de movilidad e intercambio de información.

Esta interpretación explicaría las diferencias de repertorio existentes entre LG y VQ (la cual sólo comparte un 18\% de sus TM con LG), así como las similitudes -generalesde repertorios entre VQ y las demás localidades mencionadas (cf. Cardich, 1979, 1987; Durán, 1983-1985; Gradin y Aguerre, 1983; Paunero, 2009; Paunero et al., 2005). En función de las clasificaciones estilísticas existentes para la región bajo estudio ( $c f$. Gradin, 1988; Gradin y Aguerre, 1983) y la presencia de motivos pertenecientes a los Grupos estilísticos B, B.1 y E (sensu Gradin, 1988; Gradin, Aschero y Aguerre, 1979) en la mayoría de las localidades que integran el sector sur del Macizo del Deseado (incluyendo las que se analizan en este trabajo), es posible que este circuito de movilidad e intercambio de información haya alcanzado su mayor desarrollo durante el Holoceno 
Arqueología 26(2) mayo-agosto: 127-155 (2020)— A. Acevedo y D. Fiore
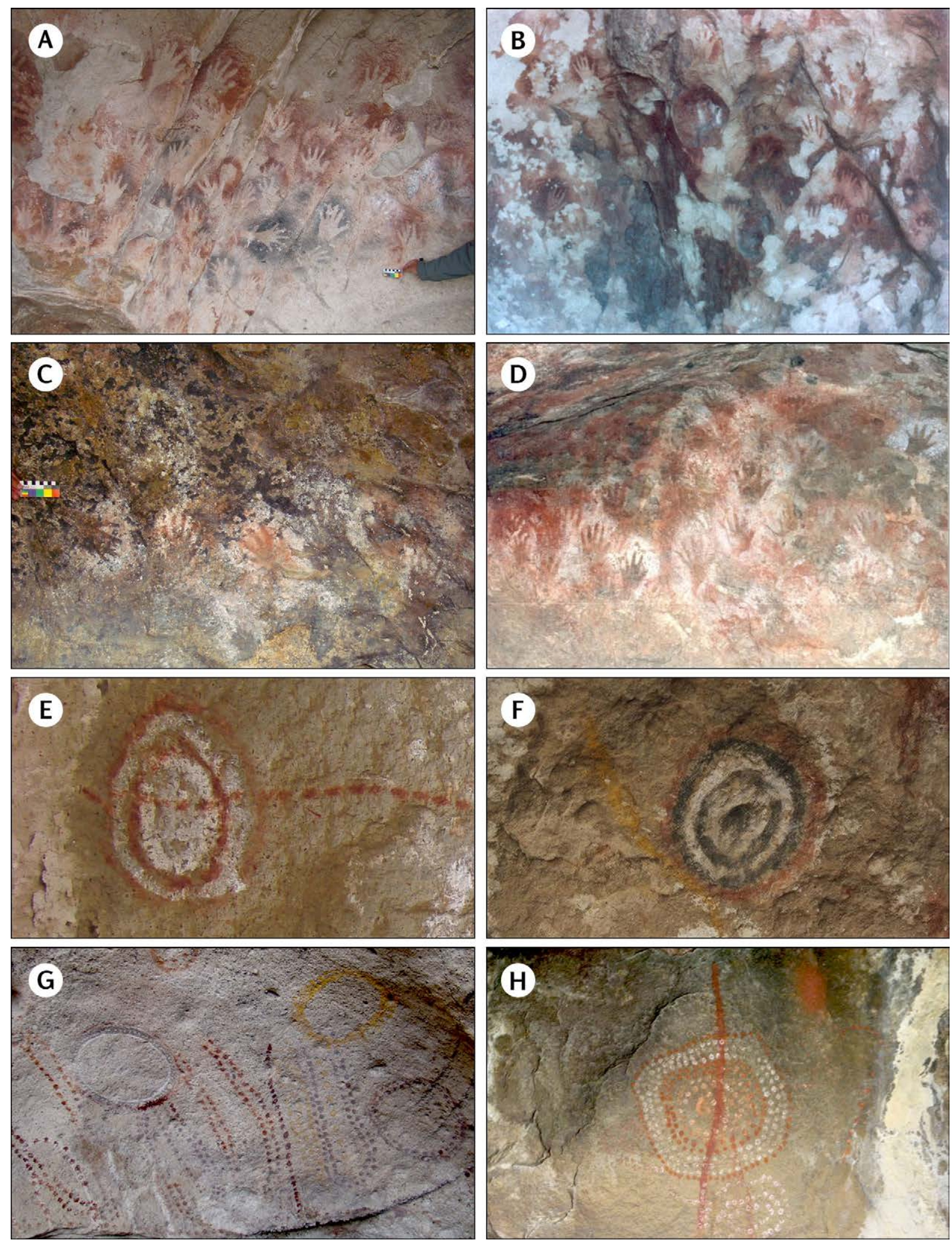

Figura 7. Conjuntos de negativos de manos, motivos geométricos y geométricos puntiformes bi-cromos y policromos: A) VQ; B) El Ceibo (Franchomme, 1987, pp. 1989); C) La Martita; D) La María (Paunero et al., 2005, lámina 3b); E y G) VQ; Fy H) La María (Paunero 2009, figura 33; Paunero et al., 2005, lámina 1D). 


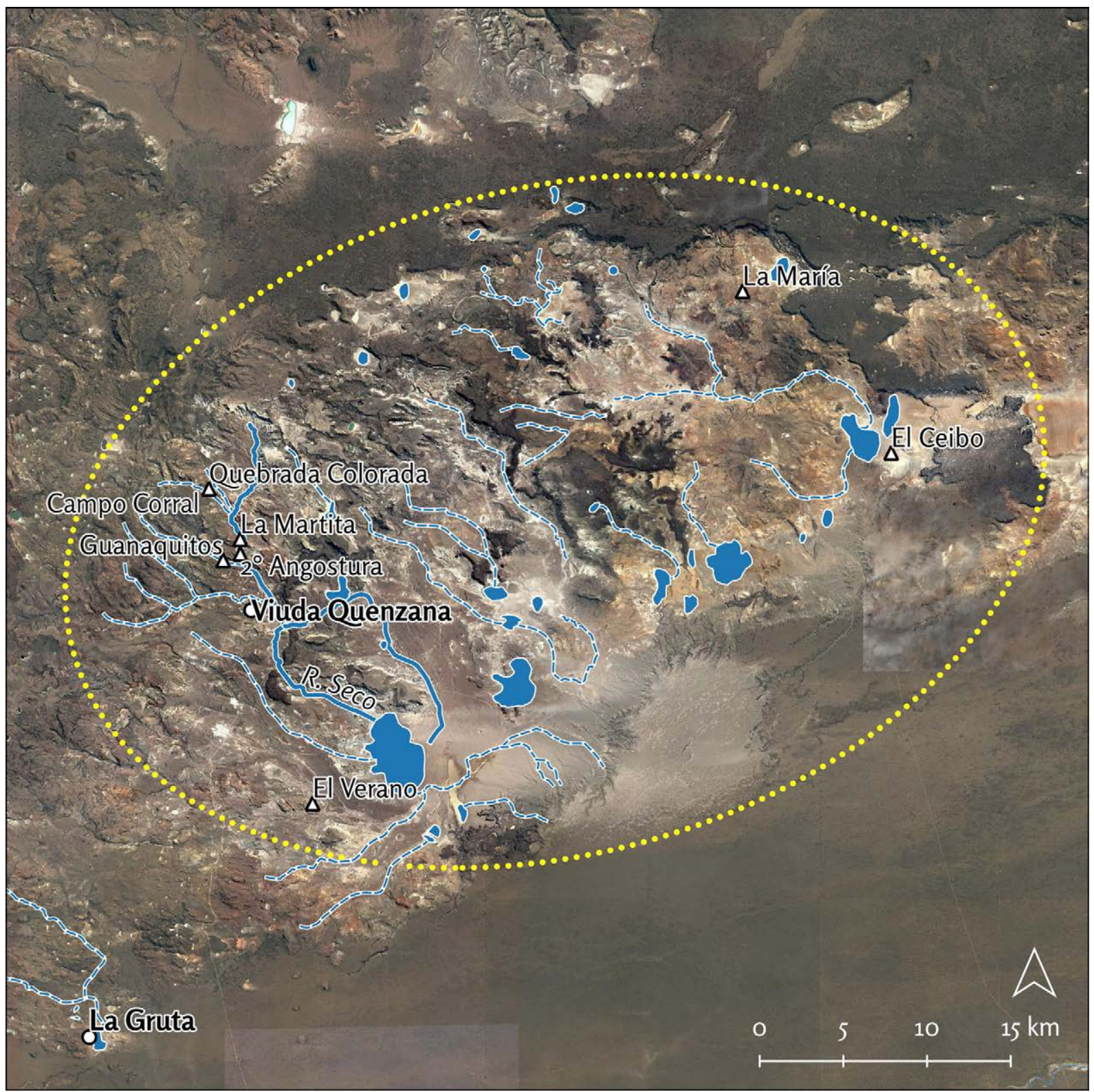

Figura 8. Potencial circuito de movilidad e intercambio de información propuesto para el Sur del Macizo del Deseado (Google Earth). En la figura se destacan los cursos y cuerpos de agua superficial muchos de ellos -actualmente-de carácter efímero o temporal.

medio y tardío ${ }^{11}$. Aunque estas inferencias, planteadas aquí de manera general, deberán ser sujetas a análisis sistemáticos inter-sitio e inter-localidad en el futuro.

A modo de cierre, el análisis de los vínculos existentes entre el arte rupestre de La Gruta y Viuda Quenzana muestra niveles básicos de comunicación visual, manifiestos en la presencia de pocos tipos de motivos en común, que comparten similitudes —únicamenteen sus aspectos formales y técnicos. Sin embargo, estos resultados no son suficientes para descartar enteramente el concepto de código visual adoptado en este trabajo. Esto se debe a que, como fuera expuesto, uno de los principales atributos del código visual reside en la selección, inclusión/exclusión y organización de elementos pertinentes para la construcción de imágenes culturalmente significativas (Dondis, 2015; Eco, 2013; Juanola Terradellas et al., 2001; Villafañe, 2006). En tal sentido, las similitudes y redundancias de producción registradas entre los tipos de motivos compartidos por La
11. Esta interpretación no descarta que el circuito planteado se haya comenzado a formar con anterioridad. La presencia de ocupaciones correspondientes al Holoceno temprano en la mayoría de las localidades que integran el sector sur del Macizo del Deseado y la existencia de motivos vinculados con el Grupo estilístico A del Área del Río Pinturas (ca. 9300 años AP; Gradin et al., 1979), en algunas de las localidades mencionadas (e.g. El Verano y La María), plantean fuertemente esta posibilidad (Aguerre, 2003: Cardich, 1979, 1987; Durán, 1983-1985; Gradin y Aguerre, 1983; Paunero et al., 2005). 
Gruta y Viuda Quenzana sugieren la existencia de operaciones de selección similares entre localidades, a partir de un mismo código visual. En los términos definidos en este trabajo, esto implica la existencia de algunas formas comunes de percepción visual fundadas sobre experiencias culturales compartidas (Anzorena, 1998; Arnheim, 1972, 1985; Eco, 2013; Villafañe, 2006; Washburn, 1983), lo cual es suficiente para sostener la existencia de comunicación visual, aunque esta haya operado de manera más sencilla y menos estructurada que lo teóricamente esperado.

\section{Agradecimientos}

Este trabajo se realizó en el marco de los proyectos PICT-2015-2038 (ANPCyT), UBACyT 20020130100664BA (UBA) y PIP $1122012010447 C O$ (CONICET), dirigidos por la Dra. Nora V. Franco. El trabajo del Dr. Agustín Acevedo se desarrolló en el marco de una Beca Interna Posdoctoral CONICET. Agradecemos a la Dra. Nora Franco, Dra. Anette Aguerre, Minera Piedra Grande, Dr. Claudio Iglesias, Minera Triton, Secretarías de Cultura y Turismo de Gdor. Gregores, Sr. Pablo Ramírez y a Natalia Cirigliano, Lucas Vetrisano, Pablo Ambrustolo y Clara Compagno por su colaboración en los trabajos de campo. Finalmente, agradecemos a los evaluadores por sus valiosas sugerencias y comentarios. 


\section{Deferencias citadas}

" Acevedo, A. (2018). El arte rupestre de la localidad arqueológica La Gruta (Patagonia, Argentina). Magallania, 46(2), 231-251.

"Acevedo, A. (2017). Arte, composición visual y paisaje. Un estudio de la producción rupestre de los grupos cazadores-recolectores de la región Extremo Sur del Macizo del Deseado (Provincia de Santa Cruz, Argentina). (Tesis Doctoral inédita), Universidad de Buenos Aires, Argentina.

» Acevedo, A. y Fiore, D. (2019). Paisajes rupestres del Extremo Sur del Macizo del Deseado: una comparación entre las localidades de La Gruta y Viuda Quenzana (Santa Cruz, Patagonia Argentina). En M. Bonnin, A. Laguens y M. B. Marconetto (Comps.), Libro de Resúmenes XX Congreso Nacional de Arqueología Argentina: 50 años de arqueologías (pp. 247-250). Córdoba: Universidad Nacional de Córdoba. Facultad de Filosofía y Humanidades.

» Acevedo, A., Fiore, D. y Franco, N. V. (2013). Imágenes en las rocas: uso del espacio y construcción del paisaje mediante el emplazamiento de arte rupestre en dos regiones de Patagonia centro-meridional (Argentina). Espacio, Tiempo y Forma, 6, 17-53.

» Acevedo, A., Fiore, D., Franco, N. V. y Ocampo, M. (2012-2014). Arte y espacio. Estructuración de los repertorios de arte rupestre en los cañadones Yaten Guajen y El Lechuza (Margen Norte del Río Santa Cruz, Patagonia, Argentina). Mundo de Antes, 8, 9-33.

"Aguerre, A. M. (1987). Investigaciones arqueológicas en el "Área de La Martita”, Departamento Magallanes, Provincia de Santa Cruz. En Comunicaciones de las Primeras Jornadas de Arqueología de la Patagonia (pp. 11-16). Rawson: Dirección Impresiones Oficiales Provincia de Chubut.

»Aguerre, A. M. (2003). La Martita: Ocupaciones de 8.000 años en la Cueva 4. En A. M. Aguerre (Ed.), Arqueología y Paleoambiente en la Patagonia Santacruceña Argentina (pp.153-204). Buenos Aires: Nuevo Offset.

» Anzorena, H. (1998). Ver para comprender. Educación desde el arte. Buenos Aires: Magisterio del Río de la Plata.

" Arnheim, R. (1972). Arte y percepción visual. Psicología de la visión creadora. Buenos Aires: Eudeba.

》Arnheim, R. (1985). El pensamiento visual. Buenos Aires: Eudeba.

» Aschero, C. (1988). Pinturas rupestres, actividades y recursos naturales; un encuadre arqueológico. En H. Yacobaccio (Ed.), Arqueología Contemporánea Argentina. Actualidad y Perspectivas (pp. 109-145). Buenos Aires: Ediciones Búsqueda.

» Aschero, C. y Martel, A. (2003-2005). El arte rupestre de Curuto-5. Antofagasta de la Sierra (Catamarca, Argentina). Cuadernos del Instituto Nacional de Antropología y Pensamiento Latinoamericano, 20, 47-72.

» Basile, M. (2012). Imágenes, recursos visuales y soportes: un recorrido por las manifestaciones rupestres de la región de fiambalá (Catamarca). Relaciones de la Sociedad Argentina de Antropología, 37(2), 413-434.

» Basile, M. y Ratto, N. (2011). Colores y surcos. Una propuesta metodológica para el análisis de las representaciones plásticas de la Región de Fiambalá (Tinogasta, Catamarca, Argentina). Boletín del Museo Chileno de Arte Precolombino, 16(2), 75-88. 
» Bird, D. y O'connell, J. (2006). Behavioral Ecology and Archaeology. Journal of Archaeological Research, 14(2), 143-188.

» Brook, G. A., Franco, N. V., Ambrústolo, P., Mancini, M. V., Wang, L. y Fernandez, P. (2015). Evidence of the earliest humans in the Southern Deseado Massif (Patagonia, Argentina), Mylodontidae, and changes in water availability. Quaternary International, $363,107-125$.

»Carden, N. (2009). Imágenes a través del tiempo. Arte rupestre y construcción social del paisaje en la Meseta Central de Santa Cruz. Buenos Aires: Sociedad Argentina de Antropología.

" Cardich, A. (1979). A propósito de un motivo sobresaliente en las pinturas rupestres de "El Ceibo" (Provincia de Santa Cruz, Argentina). Relaciones de la Sociedad Argentina de Antropología, XIII, 163-182.

" Cardich, A. (1987). Arqueología de Los Toldos y El Ceibo (Provincia de Santa Cruz, Argentina). Estudios Atacameños, 8, 98-117.

" Cirigliano, N. A. (2016). Movilidad de grupos indígenas y aprovechamientos de materias primas líticas entre el Extremo Sur del Macizo del Deseado y la Cuenca del Río Santa Cruz durante los últimos 2.000 años (Provincia de Santa Cruz, Argentina), (Tesis Doctoral inédita), Universidad de Buenos Aires, Argentina.

" Conkey, M. (1984). To find ourselves: art and social geography of prehistoric huntergatherers. En C. Shire (Ed.), Past and present in Hunter-Gatherer studies (pp. 253-276). Nueva York: Academic Press.

»Davidson, I. (en prensa). Marks, pictures, and art. Their contribution to revolutions in communication. Journal of Archaeological Method and Theory.

»Domingo Sanz, I., Fiore, D. y May, S. K. (Eds.). (2008). Archaeologies of art: time, place and identity. Walnut Creek: Left Coast Press.

»Dondis, D. A. (2015). La sintaxis de la imagen. Introducción al alfabeto visual. Barcelona: Ed. Gustavo Gili.

»Durán, V. A. (1983-1985). Arte rupestre de los cazadores patagónicos en "El Verano", Área de La Martita, Departamento Magallanes, Provincia de Santa Cruz. Anales de Arqueología y Etnología, 38-40, 43-75.

»Durán, V., Gil, A., Neme, G. y Gasco, A. (2003). El Verano: ocupaciones de 8.900 años en la Cueva 1 (Santa Cruz, Argentina). En A. Aguerre (Ed.), Arqueología y Paleoambiente en la Patagonia Santacruceña Argentina (pp. 93-120). Buenos Aires: Nuevo Offset.

» Eco, U. (2013). La estructura ausente: Introducción a la semiótica. Barcelona: Lumen.

»Fiore, D. (1996). El arte rupestre como producto complejo de procesos económicos e ideológicos: una propuesta de análisis. Espacio, Tiempo y Forma, Serie I, Prehistoria y Arqueología, 9, 239-259.

»Fiore, D. (2006). Poblamiento de Imágenes: arte rupestre y colonización de la Patagonia. Variabilidad y ritmos de cambio en tiempo y espacio. En D. Fiore y M. Podestá (Eds.), Tramas en la Piedra. Producción y usos del Arte Rupestre (pp. 43-61). Buenos Aires: Asociación Amigos del Instituto Nacional de Antropología, Sociedad Argentina de Antropología, World Archaeological Congress.

》Fiore, D. (2009). La materialidad del arte. Modelos económicos, tecnológicos y cognitivo-visuales. En R. Barberena, K. Borrazo y L.A. Borrero (Eds.), Perspectivas actuales en arqueología argentina (pp. 121-154). Buenos Aires: Consejo Nacional de Investigaciones Científicas y Técnicas, Instituto Multidisciplinario de Historia y Ciencias Humanas. 
»Fiore, D. (2011). Materialidad visual yarqueología de la imagen. Perspectivas conceptuales y propuestas metodológicas desde el sur de Sudamérica. Boletín del Museo Chileno de Arte Precolombino, 16(2), 101-119.

» Fiore, D. (2014). Archaeology of Art: Theoretical Frameworks. En C. Smith (Ed.), Enciclopedia of Global Archaeology (pp. 436-449). Heidelberg: Springer.

»Fiore, D. (2016). Las dimensiones espaciales del arte parietal. Estado actual de las investigaciones desde el Cono Sur y propuesta de síntesis metodológica. En F. Oliva, A. M. Rocchietti y F. Solomita (Eds.), Imágenes rupestres, lugares y regiones (pp. 51-62). Rosario: Universidad de Rosario, Facultad de Humanidades y Artes, Centro de Estudios de Arqueología Histórica, Centro de Estudios Arqueológicos y Regionales.

» Fiore, D. y Acevedo, A. (2015). Hunter-gatherer rock art in two regions of Central-Southern Patagonia (Argentina): visual themes, techniques and landscapes. Expression, 8, 63-68.

»Fiore, D. y Acevedo, A. (2016). El arte rupestre de la localidad Viuda Quenzana revisitado (Extremo Sur del Macizo del Deseado, Santa Cruz, Patagonia Argentina): presentación de nuevas evidencias y primeros resultados de análisis. Actas del XIX Congreso Nacional de Arqueología Argentina, Serie Monográfica y Didáctica, 54, 23182322.

»Fiore, D. y Acevedo, A. (2018). Paisajes rupestres. la identificación de patrones de producción y distribución de arte parietal en escalas espaciales amplias (Cañadón Yaten Guajen, Santa Cruz, Patagonia Argentina). Arqueología, 24(2), 177-207.

»Fiore, D., Acevedo, A. y Franco, N. V. (2017). Pintando en La Gruta: variabilidad y recurrencias en la producción de arte rupestre en una localidad del Extremo Sur del Macizo del Deseado (Santa Cruz, Patagonia, Argentina). Boletín de la Sociedad de Investigación del Arte Rupestre de Bolivia, 31, 58-74.

»Fiore, D y Posdestá, M. M. (2006). Introducción. Las tramas conceptuales del arte rupestre. En D. Fiore y M. M. Podestá (Eds.), Tramas en la Piedra. Producción y usos del Arte Rupestre (pp. 13-27). Buenos Aires: Asociación Amigos del Instituto Nacional de Antropología, Sociedad Argentina de Antropología, World Archaeological Congress.

»Franchomme, J. M. (1987). L'art Rupestre de Patagonie: quelques sites Prehistoriques du Plateau Central, Province de Santa Cruz, Argentine. (Tesis Doctoral inédita), Universidad de Paris X, Nanterre.

»Franco, N. V., Ambrústolo, P., Acevedo, A., Cirigliano, N. A. y Vommaro, M. (2013). Prospecciones en el sur del Macizo del Deseado (Provincia de Santa Cruz, Argentina). Los casos de La Gruta y Viuda Quenzana. En A. F. Zangrando, R. Barberena, A. Gil, G. Neme, M. Giardina, L. Luna, C. Otaola, S. Paulides, L. Salgán y A. Tivoli (Comps.), Tendencias teórico-metodológicas y casos de estudio en la arqueología de Patagonia (pp. 371-378). Buenos Aires: Museo de Historia Natural de San Rafael, Sociedad Argentina de Antropología, Instituto Nacional de Antropología y Pensamiento Latinoamericano.

»Franco, N. V., Ambrústolo, P. y Cirigliano, N. A. (2012). Disponibilidad de materias primas líticas silíceas en el extremo sur del macizo del Deseado: los casos de La Gruta y Viuda Quenzana (Provincia de Santa Cruz, Argentina). Magallania, 40, 279-286.

»Franco, N. V., Ambrústolo, P. y Vetrisano, L. (2015a). Materias primas líticas y su utilización en las cuencas de los ríos Chico y Santa Cruz (provincia de Santa Cruz, Patagonia argentina). Intersecciones en Antropología, 2, 113-124.

» Franco, N. V., Brook, G.A., Mancini, M. V. y Vetrisano, L. (2015b). Changes in lithic technology and environment in southern continental Patagonia: the Chico and Santa Cruz River basins. Quaternary International, 422, 57-65. 
» Franco N. V., Castro, A., Cirigliano, N. A., Martucci, M. y Acevedo, A. (2011). On cache recognition: an example from the area of the Chico river (Patagonia, Argentina). Lithic Technology, 36(1), 37-51.

» Franco, N. V., Martucci, M., Ambrústolo, P., Brook, G., Mancini, M. V. y Cirigliano, N. A. (2010). Ocupaciones humanas correspondientes a la transición Pleistoceno-Holoceno al sur del Macizo del Deseado: el área de La Gruta (provincia de Santa Cruz, Argentina). Relaciones de la Sociedad Argentina de Antropología, XXXV, 301-308.

» Gell, A. (1998). Art and agency. An anthropological theory. Oxford: Clarendon Press.

» Giraudo, S. y Martel, A. (2015). Memory, identity, power. A semiotic approach to social construction of meaning in rock art. Chinese Semiotic Studies, 11(4), 479-497.

" Gombrich, E. (1984). The sense of order. A study in the psychology of decorative art. Londres: Phaidon.

»Gradin, C. J. (1978). Algunos aspectos del análisis de las manifestaciones rupestres. Revista del Museo Provincial de Neuquén, 1, 120-133.

»Gradin, C. J. (1988). Caracterización de las tendencias estilísticas del arte rupestre de la Patagonia (provincias de Río Negro, Chubut y Santa Cruz, República Argentina). Nuevos estudios del arte rupestre argentino. Boletín SIARB, 2, 54-67.

» Gradin, C. J. (2001). El arte rupestre de los cazadores de guanaco de la Patagonia. En E. Berberián y A. Nielsen (Eds.), Historia Argentina Prehispánica (pp. 839-874). Córdoba: Brujas.

» Gradin, C. J. y Aguerre, A. M. (1983). Arte rupestre del “Área de La Martita” sección del departamento Magallanes provincia de Santa Cruz. Relaciones de la Sociedad Argentina de Antropología, XV, 195-223.

» Gradin, C. J., Aschero, C. A. y Aguerre, A. M. (1979). Arqueología del área Río Pinturas (Provincia de Santa Cruz). Relaciones de la Sociedad Argentina de Antropología, XIII, 183227.

» Harman, J. (2008). Using Decorrelation Stretch to enhance rock art images. http://www. dstretch.com/AlgorithmDescription.html (Acceso: 17 de octubre, 2018).

» Hernández Llosas, M. I. (1985). Diseño de investigación para representaciones rupestres. En Programa de Investigación y Documentación de Arte Rupestre Argentino (pp. 9-65). Buenos Aires: FECIC.

» Heyd, T. y Clegg, J. (Eds.). (2005). Aesthetics and rock art. Ashgate: Farngam.

» Juanola Terradellas, R., Sala Plana, J., Vallés Villanueva, J. y Leites De Arroyo, E. (2001). La imagen visual. Formación en artes visuales. Barcelona: Vicens Vives.

» Layton, R. (1991). The Anthropology of Art. Cambridge: Cambridge University Press.

» Leroi-gourhan, A. (1967). Treasures of prehistoric art. Nueva York: Harry Abrams.

» Lee, R. y Daly, R. (Eds.). (2002). The Cambridge Encyclopedia of Hunters and Gatherers. Cambridge: Cambridge University Press.

»Llamazares, A. M. (1986). Hacia una definición de semiosis. Reflexiones sobre su aplicabilidad para la interpretación del arte rupestre. Cuadernos del Instituto Nacional de Antropología, 11, 1-28.

» Llamazares, A. M. (1992). Imágenes e Ideología: algunas sugerencias para su estudio arqueológico. En A.S. Goldsmith, S. Garvie, D. Selin y J. Smith (Eds.), The Archaeology of Ideology, Ancient Images, Ancient Thought (pp. 151-158). Calgary: Chacmool y Archaeological Society of Alberta. 
》 Loendorf, L. (2001). Rock art recording. En D. Whitley (Ed.), Handbook of Rock Art Research (pp. 55-79). Oxford: AltaMira Press.

»Menghin, O. (1952). Las pinturas rupestres de la Patagonia. Runa, 5(1-2), 5-22.

" Menghin, O. (1957). Los estilos del arte rupestre de Patagonia. Acta Prehistórica, 1, 57-87.

" Molina, M. J. (1972). Arqueología patagónica - Arte rupestre Austral. Antiquitas 12-13, 2430.

" Morgan, C., Tushingham, S., Garvey, R., Barton, L. y Bettinger, R. (2017). Hunter-gatherer economies in the Old World and New World. En Oxford Research Encyclopedia of Environmental Science. Oxford: Oxford University Press.

"Morphy, H. (1994). The anthropology of art. En T. Ingold (Ed.), Companion Encyclopedia of Anthropology (pp. 648-685). Londres: Routledge.

" Morris, C. (1985). Fundamentos de la teoría de los signos. Barcelona: Paidós.

» Munsell Color (1994). Munsell Soil-Color Charts. New Windsor: Macbeth Division of Kollmorgen Instruments.

»Panza, J. L. y Marín, G. (1998). Hoja Geológica 4969-I Gobernador Gregores, Provincia de Santa Cruz. Programa Nacional de Cartas Geológicas de la República Argentina 1:250.000. Boletín $N^{\circ}$ 239. Buenos Aires: Secretaría de Minería de la Nación. Dirección Nacional del Servicio Geológico.

"Paunero, R. (2009). El arte rupestre milenario de Estancia La María, Meseta Central de Santa Cruz. San Julián: Municipalidad de Puerto San Julián.

»Paunero, R. S., Frank, A. D., Skarbun, F., Rosales, G., Zapata, G., Cueto, M. E., Paunero, M. F., Martinez, D. G., López, R., Lunazzi, N. y Del Giorgio, M. (2005). Arte Rupestre en Estancia La María, Meseta Central de Santa Cruz: Sectorización y contextos arqueológicos. Relaciones de la Sociedad Argentina de Antropología, XXX, 147-168.

»Pierce, C. (1974). La ciencia de la semiótica. Buenos Aires: Nueva Visión.

" Re, A. (2010). Representaciones rupestres en mesetas altas de la provincia de Santa Cruz. Circulación de información en espacios de uso estacional. (Tesis Doctoral inédita), Universidad de Buenos Aires, Argentina.

» Ucko, P. J. y Rosenfeld, A. (1967). Palaeolithic cave art. Londres: University Library.

»Villafañe, J. (2006). Introducción a la teoría de la imagen. Madrid: Pirámide.

"Whitely, D. (1994). By the hunter, for the gatherer: art, social relations and subsistence change in the prehistoric Great Basin. World Archaeology, 25, 356-373.

»Washburn, D. (1983). Toward a theory of structural style in art. En D. Washburn (Ed.), Structure and cognition in art. New Directions in Archaeology (pp. 1-7). Cambridge: Cambridge University Press.

"Wobst, H. M. (1977). Stylistic Behavior and Information Exchange. En E.H. Cleland (Ed.), For the Director. Research Essays in Honor of James B. Griffen (pp. 317-342). Ann Arbour: Anthropological Papers, University of Michigan Museum of Anthropology. 